\title{
When Creativity Strikes: News Shocks And Business Cycle FLUCTUATIONS
}

\author{
Silvia Miranda-Agrippino* \\ Bank of England \\ Centre for Macroeconomics (LSE)
}

\author{
Sinem Hacioğlu Hoke ${ }^{\dagger}$ \\ Bank of England \\ Data Analytics for Finance and Macro (KCL) \\ Kristina Bluwstein $\ddagger$ \\ Bank of England
}

August 22, 2018

\begin{abstract}
We use monthly US utility patent applications to construct an external instrument for identification of technology news shocks in a rich-information VAR. Technology diffuses slowly, and affects total factor productivity in an S-shaped pattern. Responsible for about a tenth of economic fluctuations at business cycle frequencies, the shock elicits a slow, but large and positive response of quantities, and a sluggish contraction in prices, followed by an endogenous easing in the monetary stance. The ensuing economic expansion substantially anticipates any material increase in TFP. Technology news are strongly priced-in in the stock market on impact, but measures of consumers' expectations take sensibly longer to adjust, consistent with a New-Keynesian framework with nominal rigidities, and featuring informationally constrained agents.
\end{abstract}

Keywords: Technology News Shocks; Business Cycle; Identification with External Instruments; Patents Applications.

JEL Classification: E23, E32, O33, E22, O34

\footnotetext{
*Monetary Analysis, Bank of England, Threadneedle Street, London EC2R 8AH, UK. E-mail: silvia.miranda-agrippino@bankofengland.co.uk Web: www.silviamirandaagrippino.com

${ }^{\dagger}$ Financial Stability, Strategy and Risk. E-mail: sinem.hacioglu@bankofengland.co.uk Web: www. sinemhaciogluhoke.com

${ }^{\ddagger}$ Financial Stability, Strategy and Risk. E-mail: kristina.bluwstein@bankofengland.co.uk Web: www.kristinabluwstein.com/
}

is We are grateful to Franck Portier, Michael McMahon, Emanuel Mönch, and seminar participants at the Bank of England for useful comments and discussions. We thank Luca Gambetti for sharing his code on the information sufficiency test. The views expressed in this paper are those of the authors and do not reflect those of the Bank of England or any of its Committees. 


\section{Introduction}

The idea that changes in agents' beliefs about the future may be an important driver of economic fluctuations has fascinated many scholars over the years. While the application to technology news is relatively recent, and has been revived following the seminal contributions of Beaudry and Portier (2004, 2006), the insight that changes in agents' expectations about future fundamentals could be a dominant source of economic fluctuations is a long-standing one in Economics (see e.g. Pigou, 1927). The news-driven business cycle hypothesis posits that business cycle fluctuations can arise because of changes in agents' expectations about future economic fundamentals, and absent any actual change in the fundamental themselves. If the arrival of favorable news about future productivity can originate an economic boom, lower than expected realized productivity can set off a bust without any need for a change in productivity having effectively occurred. The plausibility of belief-driven business cycles is however still a hotly debated issue in the literature (see e.g. the extensive review in Ramey, 2016). ${ }^{1}$

In this paper, we set to answer a slightly different, but related question: 'How does the aggregate economy react to a shock that raises expectations about future productivity growth?' We provide an empirical answer to this question in a rich-information quarterly VAR that incorporates many of the relevant aggregates, such as output, consumption, investment and labor inputs, as well as forward looking variables such as asset prices, interest rates, and consumer expectations. The novelty in our approach resides in the identification of technology news shocks: we construct an external instrument for identification by using the unforecastable component of all monthly utility patent applications

\footnotetext{
${ }^{1}$ The empirical literature on technology news shocks is vast, and we review it when discussing our results in Sections 4 and 5 . At the poles of the debate are the advocates of the news-driven business cycle hypothesis such as e.g. Beaudry and Portier (2006, 2014); Beaudry and Lucke (2010), and its opponents, such as e.g. Barsky and Sims (2011, 2009); Kurmann and Otrok (2013); Barsky et al. (2015); Kurmann and Sims (2017). In Beaudry and Portier (2006) news shocks are orthogonal to current productivity, but are the sole driver of TFP in the long run (e.g. Galí, 1999; Francis and Ramey, 2005). Other works have identified technology shocks as those maximizing the forecast error variance of productivity at some long finite horizon (e.g. Francis et al., 2014), or over a number of different horizons (see e.g. Barsky and Sims, 2011). Other contributions have highlighted the differences arising from e.g. modeling variables in levels rather than in first differences, allowing for cointegrating relationship among variables (together with their number and their specification), accounting for low frequency structural breaks, accounting for other policy-related concomitant factors, and enriching the information set in the VAR. Examples include Christiano et al. (2003); Fernald (2007); Francis and Ramey (2009); Mertens and Ravn (2011); Forni et al. (2014).
} 
filed at the U.S. Patents and Trademark Office (USPTO) over the past thirty years. The starting point for the construction of our external instrument are the "USPTO Historical Patent Data Files" (Marco et al., 2015) that provide a comprehensive record of all publicly available applications and granted patents registered at the USPTO from January 1981 to December 2014. To the best of our knowledge, the properties of monthly patent applications have not been previously explored in empirical macroeconomics, or in the context of identifying technology news shocks. ${ }^{2}$ The protection granted to new inventions through the patenting system constitutes a powerful incentive to file appropriate applications before they are diffused and commercialized. Hence, patents applications at any point in time embed a signal about potential future technological changes. At the same time, however, the decision of filing a patent is a fundamentally endogenous one. On the one hand, R\&D expenditures may be systematically more generous in times of economic boom, endogenously leading to a higher number of patents applications. On the other, individuals and businesses may strategically time application filings depending on their expectations about future economic developments, to the extent that these may influence their future profit margins. We move from this intuition to construct our instrument for identification of technology news shocks.

Specifically, we recover the external instrument as the component of patent applications that is orthogonal to (i) its own lags; (ii) a selection of forecasts at different horizons intended to capture current or expected macroeconomic developments that may influence the decision of filing a patent in the time unit, and which we take from the Survey of Professional Forecasters; and (iii) other contemporaneous unanticipated monetary and fiscal policy changes. Contrary to virtually all the existing literature, our identification strategy allows to dispense from potentially strong a priori assumptions related to the duration of the effects of news shocks, the long-run drivers of technology, or the length of time that is required to the news to affect the current level of technology. Moreover, it is robust to mismeasurements in commonly used empirical measures of aggregate

\footnotetext{
${ }^{2}$ Earlier studies that have similarly employed patents applications to measure the effects of technology shocks (reviewed below) have typically relied on annual data. The use of patent data to measure technological advancements at industry level dates back at least to Lach (1995). Griliches (1990) provides a review of the uses of patent data in economic analysis, and in particular as indicators for technological change. Hall and Trajtenberg (2004) use the annual NBER patent citations data file described in Hall et al. (2001) to show that granted patents, and their citations, can be used to measure evidence of General Purpose Technologies (GPT).
} 
technology (see e.g. discussions in Fernald, 2014; Kurmann and Sims, 2017). The identifying assumptions in our SVAR-IV (Mertens and Ravn, 2013; Stock and Watson, 2012, 2018) are that the instrument is informative about technology news, and that this is the only channel through which the instrument and the VAR innovations are related (Miranda-Agrippino and Ricco, 2018). Importantly, because innovations can in principle be released to the public under a 'patent-pending' status, our identification scheme does not warrant imposing orthogonality with respect to the current level of technology, which is instead a standard assumption in the news literature (see e.g. Beaudry and Portier, 2006; Barsky and Sims, 2011, among many others). In this respect, our identification is akin to Barsky et al. (2015); Kurmann and Sims (2017). These papers relax the assumption that technology news should have a zero impact effect on current TFP levels on the basis that news about future productivity can arrive along with innovations in current technology, that innovations to current technology may signal significant improvements in the following years, and that technology slowly diffuses across sectors. We subscribe to this interpretation.

While such orthogonality condition is not imposed a priori, our external instrument recovers a news shock that has essentially no effect on TFP either on impact, or in the two years immediately afterwards. TFP then rises robustly following a persistent hump that reaches a peak 6 to 7 years after the shock hits. The time that it takes for news to translate into meaningful changes in future TFP is sensibly longer than the two-year anticipation lag that is typically assumed in the literature (see e.g. Schmitt-Grohé and Uribe, 2012; Beaudry and Portier, 2014; Faccini and Melosi, 2018). Instead, both the shape and timing of the TFP response are consistent with the S-shaped pattern that is typical of the slow diffusion of new technologies documented, among many others, in Griliches (1957); Rogers (1962) and Gort and Klepper (1982).

Conversely, by the time TFP materially departs from its initial level, the dynamics of all other variables in our VAR are largely exhausted, and virtually all have comfortably returned back to trend. The arrival of news about future technological improvements triggers a sustained, albeit delayed, economic expansion: output, consumption, investment, hours worked and capacity utilization all rise to peak at the two-year horizon. ${ }^{3}$ Hence,

\footnotetext{
${ }^{3}$ Initial responses, while numerically negative, are not significant at conventional levels, with the
} 
the pattern of dynamic responses that we recover does lend credit to a 'news-view' in the spirit of what described in e.g. Beaudry and Portier (2006). In recent influential work, Chahrour and Jurado (2018b) have proven that any model with news has an observationally equivalent noise representation. In other words, a framework in which agents receive some advance information about the realization of future fundamentals can be recast in an observationally equivalent representation in which agents receive a noise-ridden signal about future fundamentals, and form their expectations by solving a signal extraction problem. Seen through these lenses, news - that are realized on average -, confound the effects of 'pure beliefs' with those associated with changes in future fundamentals. Conversely, noise, orthogonal to fundamentals at all leads and lags, captures the essence of 'pure beliefs'. The large asynchronicity in the timing of the estimated dynamic responses seems to suggest that the aggregate effects of technology news that we unveil may be predominantly (if not entirely) driven by beliefs. ${ }^{4}$ The shock that we recover, however, is not the main driver of economic fluctuations. At business cycle frequencies, only about a tenth (on average) of aggregate fluctuations is accounted for by the estimated news shock; importantly, we also find that it only accounts for at most $40 \%$ of the variation of TFP in the very long run. This finding may potentially have implications for identification schemes that rely on 'max-share' of explained TFP variation (e.g. Barsky and Sims, 2011; Kurmann and Otrok, 2013, among many others).

The pattern of dynamic responses that we recover is consistent with the predictions of New Keynesian models with nominal rigidities, particularly those where such frictions arise due to imperfect common knowledge (e.g. Mankiw and Reis, 2002; Woodford, 2003). After an inertial initial reaction, prices eventually decline. Conversely, real wages rise at medium horizons, but contract on impact. The monetary authority endogenously responds to the fall in (expected) inflation by lowering nominal rates on impact, and more

exception of hours worked, that suffer a moderate and very brief contraction, and consumption, that instead rises already upon realization of the shock. Similar types of impact responses are documented in Francis and Ramey (2005); Basu et al. (2006) and Barsky and Sims (2011).

${ }^{4}$ Comparing findings in Schmitt-Grohé and Uribe (2012); Barsky and Sims (2012) and Blanchard et al. (2013), Chahrour and Jurado (2018b) note that these models all concur that future fundamentals play a negligible role in driving aggregate fluctuations. In fact, for future fundamentals to play a significant role, it must be the case that both agents' actions depend on their expectations about the future, and that they have access to accurate information about the future that is not revealed by either current or past fundamentals. 
than proportionally. Hence, real short-term rates decline at a time when the natural rate of interest, proportional to the expected growth rate of technology, is rising (see e.g. Christiano et al., 2010). This suboptimal response of the central bank can also be rationalized in terms of information rigidity: the central bank responds to its best forecast of current and future fundamentals, that may diverge from actual realizations (see e.g. discussion in Lorenzoni, 2011; Sims, 2012a). A noisy signal about future technological changes can also be responsible for agents overweighting current conditions when forming expectations about the future (see e.g. Coibion and Gorodnichenko, 2015). In this sense, the initial rise in consumers' expectations about future unemployment that we document is consistent with the initial deterioration in labor market conditions, reflected in the fall of both hours worked, and wages. In turn, this can help explain the initial downward revision in consumers' expectations about current conditions, and expected business outlook five years hence. In this respect, our results suggest caution in interpreting innovations in consumer confidence indicators as a 'pure' measure of news (e.g. Cochrane, 1994; Barsky and Sims, 2012). Finally, we find evidence of a potential amplification channel for news shocks that works through the compression of risk (term) premia, in turn consistent with the decoupling of asset prices and interest rates on the one hand, and consumption growth and inflation on the other (see also Crump et al., 2016).

Our work is closely related to a stream of studies that has relied on empirical measures of technological changes in order to identify the effects of technology shocks. The first such study is Shea (1999). Here annual patent applications and R\&D expenditures are used to estimate the effects of technology shocks on industry aggregates. Identification is achieved by ordering either measure last in a battery of small-scale VARs that also contain labor inputs and productivity. Christiansen (2008) extends on the previous study by using over a century of annual patent application data. The benchmark specification is a bivariate VAR with labor productivity and patents ordered first. Alexopoulos (2011) uses the number of book titles published in the field of technology to construct a measure for technological changes intended to capture the time in which the novelty is effectively commercialized. Responses of aggregate variables are estimated in a set of bivariate VARs with the publication index ordered last. More recently, Baron and Schmidt (2014) have used technology standards and a Cholesky factorization with the standard 
variable ordered last to infer on the aggregate implications of anticipated technology shocks, and also report evidence of a slow diffusion of technology over time. For what concerns the chronological placement in terms of anticipation lag, for each technological improvement, industry standardizations sit somewhere in between patent applications and the publication of the relevant title. ${ }^{5}$ Our paper differs from these contributions in several ways. First, these studies address the fundamental endogeneity of empirical measures of technological changes only to the extent that this is captured in the reminder of variables included in the bi/tri-variate VARs. Other than relying on a richer VAR specification, in the construction of our instrument we recognize that the cyclical nature of patents applications may be influenced also by expected future realizations, which we capture using an array of survey forecasts at different horizons, and by other concomitant policy changes. Second, and related, these studies have all implicitly assumed the empirical measure of technology being a near perfect measure of news shocks. In fact, their identifying assumptions amount to effectively retrieving the transmission coefficients by running a distributed lag regression (with some controls) of the variables on the patents data. In contrast, our identifying assumptions explicitly account for the possible presence of measurement error in the constructed instrument. Finally, these studies have all relied on annual data potentially overlooking important higher frequency variation which instead we exploit for the identification.

The structure of the paper is as follows. Section 2 introduces the external instrument that we design for the identification of technology news shocks, and describes the monthly patent data that we use for its construction. Section 3 discusses common challenges to the empirical identification of technology news shocks in VARs and lays out the identification assumptions in our SVAR-IV. Section 4 collects the results, which we discuss in detail in Section 5 against the main transmission mechanisms proposed in the literature. Finally, Section 6 concludes.

\footnotetext{
${ }^{5}$ In an international context, Arezki et al. (2017) use giant oil discoveries as a directly observable measure of technology news shocks and estimate their effects in a dynamic panel distributed lag model.
} 


\section{A Patents-Based Instrument for News about Fu- ture Technological Changes}

In the vast majority of industries, and particularly since the $20^{\text {th }}$ century, the introduction of technological innovations follows a relatively standardized process. Typically, before an invention - intended as either a brand new product or production process, as well as an amelioration to existing ones - is disclosed, the owner proceeds to file a patent application in order to protect her creation. The legal protection that is granted to patent holders ensures that an individual or business has a set number of years in which to capitalize on their invention. Hence, the incentive to protect new inventions through appropriate patent registrations is high. The length of time that elapses from the time in which a patent application is filed to when it is then granted, and the invention eventually diffuses within the economy, can be in the order of several years, depending on the type of patent and the characteristics of the industry sector. Hence, patents applications at any given time contain information about technological changes that will occur at some point in the future (see e.g. Lach, 1995; Hall and Trajtenberg, 2004). At the same time, although the bulk of informativeness of patents applications lies in the future, and patented products cannot be copied by others during the protected period, some inventions are often released to the public under a 'patent-pending' status. This initial diaspora of the invention spreads new knowledge to the public, some of whom may be able to improve upon that invention themselves. Hence, it is conceivable that patents applications may potentially also embed a signal for current technological changes. We move from this intuition to construct an external instrument for identification of technology news shocks.

The decision to file a patent application at any given time is, however, a fundamentally endogenous one. On the one hand, R\&D expenditures may be systematically more generous in times of economic boom, endogenously leading to a higher number of patents applications. On the other, individuals and businesses may strategically time application filings depending on their expectations about future economic developments, to the extent that this may influence their future profit margins. Separately, not all patent applications result in a grant, and hence the signal about future productivity changes is necessarily only a partial one. This can raise concerns relative to the relevance of the 
instrument. We address these issues in more detail in the next subsection, where we also describe the patent dataset. We then go on to detail the construction of the external instrument at the end of the section.

\subsection{Information in Patent Data}

We use the "US Patents and Trademark Office (USPTO) Historical Patent Data Files" compiled by Marco et al. (2015) as a follow up and extension of Hall et al. (2001). The dataset records the monthly stocks and flows of all publicly available applications, published and unpublished, and granted patents registered at the USPTO from January 1981 to December 2014. The stocks include pending applications and patents-in-force; flows include new applications, patent grants and abandonments. ${ }^{6}$

Our starting point for the analysis is the monthly flow of all new utility patent applications. ${ }^{7}$ We then construct quarterly variables by summing up the monthly flows within each quarter. Figure I plots (the cumulated sum of) quarterly patent applications from 1981 to 2014, for each of the NBER categories defined in Marco et al. (2015), and reported in Table C.II in Appendix C. In the figure, shaded areas denote NBER recession episodes, and we normalize 1981-I to be equal to 0 to highlight the different trends across different categories. The number of new patents applications has increased substantially over the past 30 years and, as visible from the chart, patents classified under 'computers and communications' (orange line) have enjoyed a faster trend. Patent applications across all categories tend to slide after recessionary episodes, providing some evidence on their cyclical nature.

There have been three important regulatory changes in patenting in 1982, 1995, and 2013. All these regulations affected the number of applications when they came into effect, as shown by the spikes in Figure I. In 1982, the old Court for Customs and Patent

\footnotetext{
${ }^{6}$ See also Hall et al. (2001). The dataset is available for download at http://www.ustpo.gov/ economics.

${ }^{7}$ We discard information relative to both abandonments and patents granted. While granted patents can potentially provide a stronger signal about future technological changes, they tend to be significantly more cyclical than patents applications. Also, the production of the invention may already have started while the application was pending. Hence, most of the 'news content' in patent applications may be exhausted by the time it is granted. And this is particularly true after the regulatory changes which made patent applications public after 2000. Moreover, as Christiansen (2008) discusses, the issuance depends highly on the intensity of labor and administrative cycles in the USPTO in any given time period.
} 


\section{Figure I: Patent Applications across NBER Classifications}

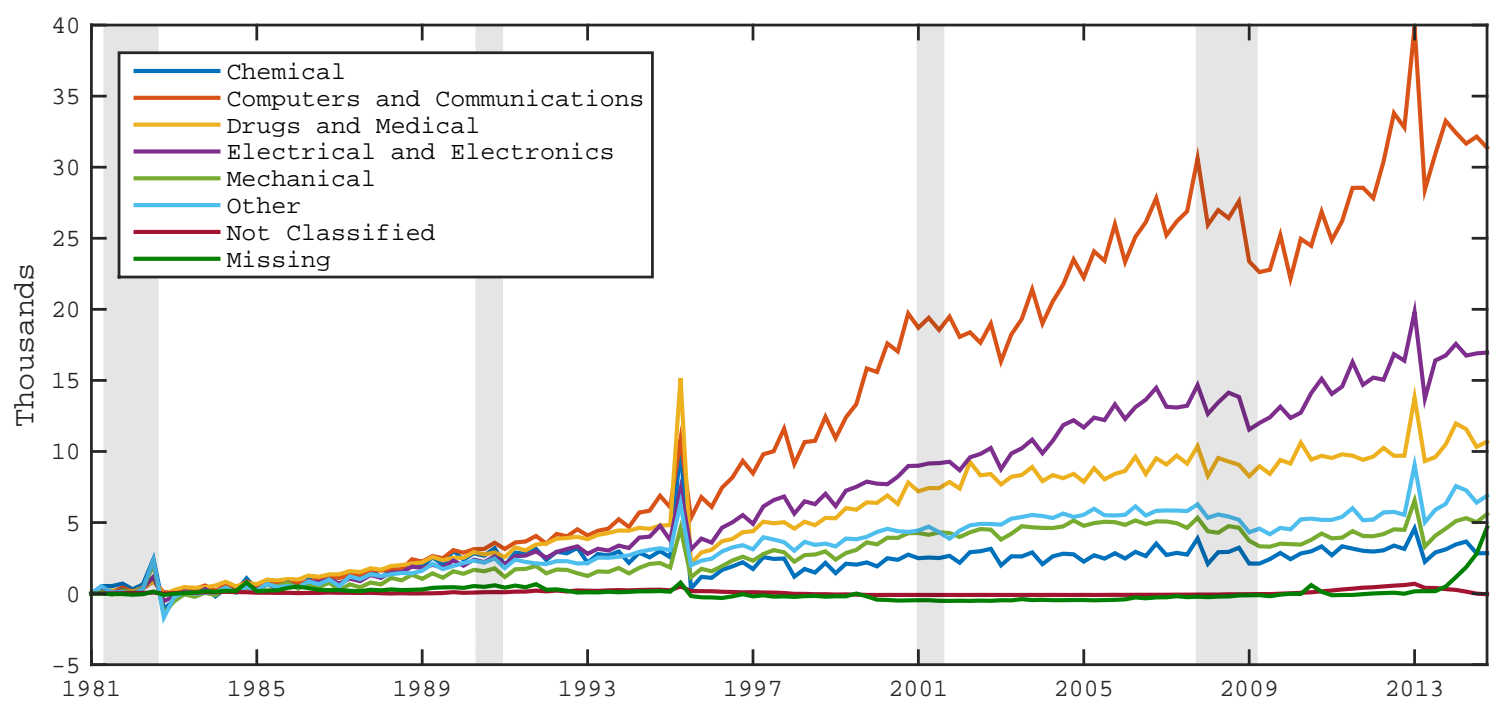

Note: Patents applications across all NBER categories. Quarterly figures obtained as sum of monthly readings, 1981-Q1=0. Shaded areas denote NBER recession episodes.

Appeals was abolished and a new Court of Appeals for the Federal Circuit was established; the new court provided more protection to the owners of patents against infringement. In 1995, the U.S. implemented the changes agreed upon in the Agreement on TradeRelated Aspects of Intellectual Property Rights (TRIPS) as part of the Uruguay Round Agreements Act. The TRIPS agreement's main purpose was to harmonize patenting rules among all members of the World Intellectual Property Organization (WIPO). The large impact on the number of patent filings was due to a change in patent terms; as of June 1995, patent terms were set to 20 years from filing, and away from the previous practice of 17 years after issuance. Finally, in March 2013, the U.S. implemented the rules under the America Invents Acts (AIA). These sets of rules were designed to address the right to file a patent application, and implied that applications filed on or after March 2013 were to be governed under the new priority rule 'first-inventor-to-file', rather than the pre-existing 'first-to-invent'. ${ }^{8}$ All these three regulatory changes led to an increase in applications prior to their implementation. However, to the extent that they are not driven by considerations related to current or anticipated economic conditions, they

\footnotetext{
${ }^{8}$ For a detailed description of the Leahy-Smith America Invents Act the reader is referred to https: //www.uspto.gov/sites/default/files/aia_implementation/20110916-pub-1112-29.pdf
} 
provide us with important sample variation which we exploit for the identification.

The proportion of patent applications that eventually results in a grant being issued can vary substantially, both over time, and across categories. ${ }^{9}$ To give a sense of the time evolution and the success (allowance) rates, in Appendix $\mathrm{C}$ we report a set of summary statistics which we take from both Carley et al. (2015) and Marco et al. (2015). Allowance rates vary whether one considers 'first-action', 'progenitor', or 'family' allowance rates. ${ }^{10}$ Family allowance rates tend to be the highest by their nature, with success rates peaking at over $80 \%$. At the other end of the spectrum, first-action allowance rates, allowed without the need for further amendments, are the least successful with average allowance rates of about $10 \%$. Progenitor allowance rates sit somewhere in the middle, with a lowest reading of about $43 \%$ (Figure C.I). Hence, while not all applications result in granted patents, the share of successful applications is substantial. This supports the intuition that patents applications give a strong signal about future technological changes. A further piece of evidence is in Figure C.II, taken from Marco et al. (2015). The chart considers the cohort of applications filed in 2002, across all the NBER categories. Success rates range from $57 \%$ in 'drugs \& medical', to $81 \%$ in 'electrical \& electronics'.

We explore the properties of quarterly patents applications in Table I. Here we regress the quarterly growth rate of all utility patents applications (excluding 'non-classified' and 'missing') on its first four lags, and on a collection of expectations about the economy sampled at different forecast horizons, and taken from the Survey of Professional Forecasters $(\mathrm{SPF})$. The vector of forecasts $\mathbb{E}_{t}\left[w_{t+h}\right]$ includes real output growth, the unemployment rate, inflation (GDP deflator), real federal government spending, real non-residential investments, and real corporate profits net of taxes. ${ }^{11}$ The forecast horizon is expressed in quarters, such that $\mathbb{E}_{t}\left[w_{t}\right]$ denotes SPF forecasts for the current quarter. ${ }^{12}$ Regres-

\footnotetext{
${ }^{9}$ From filing to issuance, the process takes on average 2 years as documented by Marco et al. (2015).

${ }^{10}$ The first-action allowance rate is the proportion of progenitor applications that are allowed without further examination. The progenitor allowance rate (or simply, allowance rate) is the proportion of progenitor applications allowed without any continuation procedure. The family allowance rate is the proportion of applications that produce at least one patent, including the outcomes of continuation applications that emerge from progenitor applications (see Carley et al., 2015).

${ }^{11} \mathrm{SPF}$ respondents forecast nominal corporate profits net of taxes. We construct a series for real corporate profits forecasts by deflating with the forecasts for the GDP deflator (our measure of inflation, see Section 4) at the relevant forecast horizons.

${ }^{12} \mathrm{SPF}$ forecasts are published in the middle of the second month of each quarter. The information set of the respondents at the time of compiling the survey includes the advance report on the national income and product accounts of the Bureau of Economic Analysis, which is published at the end of the first month
} 


\section{Table I: Endogeneity of Patents Applications}

\begin{tabular}{|c|c|c|c|c|}
\hline & (1) & (2) & (3) & (4) \\
\hline$p a_{t-1}$ & $\begin{array}{l}-0.850^{* * *} \\
(-8.93)\end{array}$ & $\begin{array}{l}-0.943^{* * *} \\
(-10.18)\end{array}$ & $\begin{array}{l}-0.932^{* * *} \\
(-9.81)\end{array}$ & $\begin{array}{l}-0.894^{* * *} \\
(-10.20)\end{array}$ \\
\hline$p a_{t-2}$ & $\begin{array}{l}-0.481^{* * *} \\
(-4.61)\end{array}$ & $\begin{array}{l}-0.640^{* * *} \\
(-6.36)\end{array}$ & $\begin{array}{l}-0.640^{* * *} \\
(-6.35)\end{array}$ & $\begin{array}{l}-0.592^{* * *} \\
(-6.00)\end{array}$ \\
\hline$p a_{t-3}$ & $\begin{array}{l}-0.275^{* * *} \\
(-3.20)\end{array}$ & $\begin{array}{l}-0.441^{* * *} \\
(-5.41)\end{array}$ & $\begin{array}{l}-0.428^{* * *} \\
(-5.54)\end{array}$ & $\begin{array}{l}-0.389^{* * *} \\
(-5.74)\end{array}$ \\
\hline$p a_{t-4}$ & $\begin{array}{l}0.001 \\
(0.01)\end{array}$ & $\begin{array}{l}-0.077 \\
(-1.00)\end{array}$ & $\begin{array}{l}-0.078 \\
(-1.03)\end{array}$ & $\begin{array}{l}-0.067 \\
(-0.90)\end{array}$ \\
\hline $\mathbb{E}_{t}\left[w_{t}\right]$ & & $\begin{array}{l}5.575^{* * *} \\
0.000\end{array}$ & & \\
\hline $\mathbb{E}_{t}\left[w_{t+1}\right]$ & & & $\begin{array}{l}7.955^{* * *} \\
0.000\end{array}$ & \\
\hline $\mathbb{E}_{t}\left[w_{t+4}\right]$ & & & & $\begin{array}{l}4.158^{* * *} \\
0.001\end{array}$ \\
\hline $\begin{array}{l}\text { regulation } \\
\text { dummy }\end{array}$ & & $\checkmark$ & $\checkmark$ & $\checkmark$ \\
\hline constant & $\checkmark$ & $\checkmark$ & $\checkmark$ & $\checkmark$ \\
\hline $\operatorname{Adj}-R^{2}$ & 0.448 & 0.794 & 0.791 & 0.767 \\
\hline $\mathrm{N}$ & 131 & 131 & 131 & 131 \\
\hline
\end{tabular}

Notes: Granger Causality. Dependent variable: $p a_{t}=100 \times\left(\ln P A_{t}-\ln P A_{t-1}\right)$, quarterly growth rate of utility patents applications registered at the USTPO. $\mathbb{E}_{t}\left[w_{t+h}\right]$ denotes SPF forecast published in quarter $t$. The forecast horizon is expressed in quarters. $w_{t}$ contains forecasts for real output growth, the unemployment rate, inflation (GDP deflator), real federal government spending, real non-residential investments, and real corporate profits net of taxes. The regulation dummy captures the legal changes in the patents application process implemented in September 1982, June 1995, and March 2013. Top panel: $t$ statistics in parentheses, robust standard errors. Middle panel: Wald test statistics for joint significance of SPF forecasts. $*, * *, * *$ denote statistical significance at 10,5 , and $1 \%$ respectively.

sions include a constant and a regulatory dummy intended to capture the legal changes discussed above. We report $t$-statistics for the autoregressive coefficients, and Wald test statistics for the joint significance of SPF forecasts at each horizon. Standard errors are HAC-corrected.

Patent applications exhibit a strong autocorrelation pattern. Moreover, as anticipated, there is evidence that current and expected economic conditions can influence the decision of filing patent applications in any given quarter. Patents applications also correlate with the first (lagged) factor extracted from the large collection of US macroeconomic and financial data assembled in McCracken and $\mathrm{Ng}$ (2015). Results are reported in Table C.I. Typically, the first such factor is interpreted as a measure of economic activity. This in each quarter. For further information see https://www.philadelphiafed.org/research-and-data/ real-time-center/survey-of-professional-forecasters. 
Figure II: Instrument FOR News SHOCKS

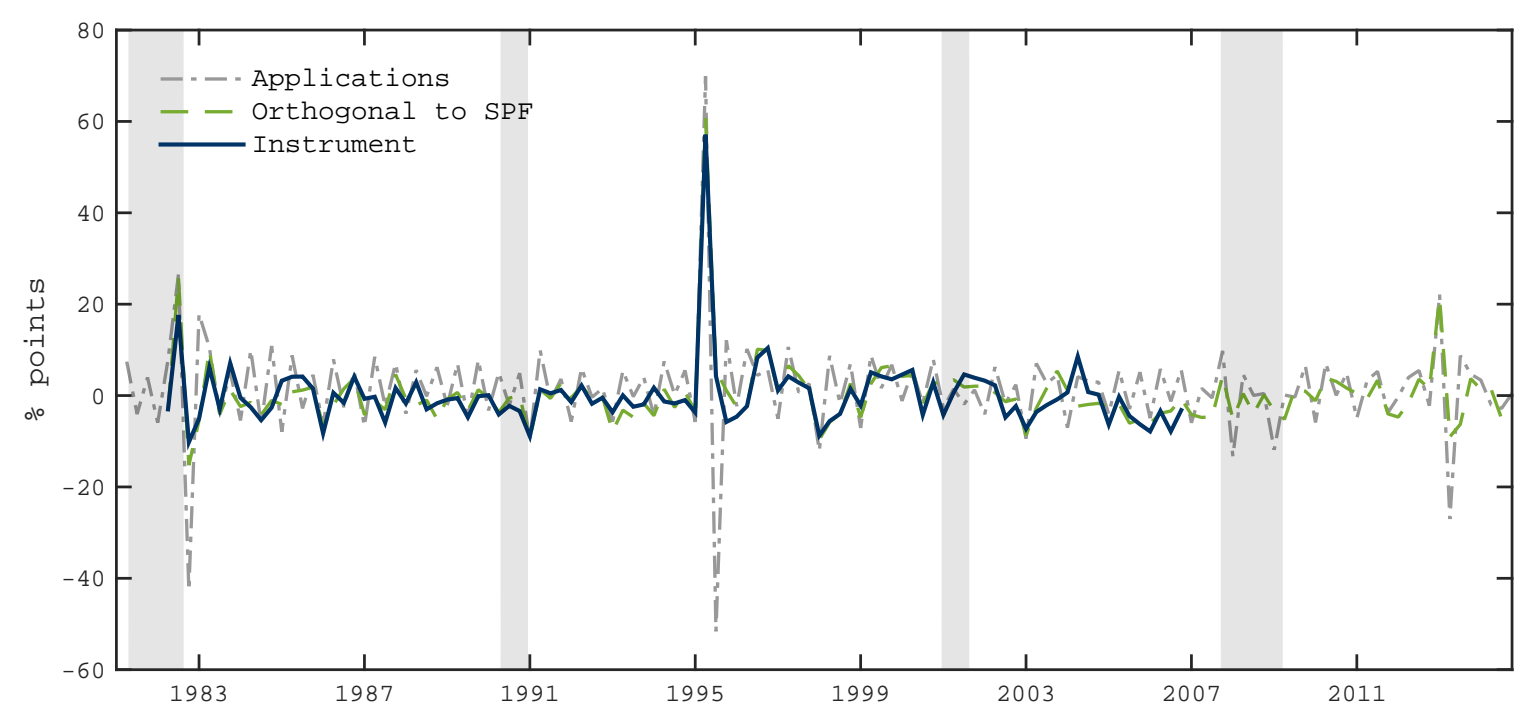

Note: Raw count of patent applications, quarterly growth rate (grey, dash-dotted line). Instrument for news shocks (green, dash-dotted line), residuals of Eq. (1). Shaded areas denote NBER recession episodes.

too reinforces the fundamentally cyclical nature of patents applications.

In the next subsection, we construct an instrument for identification of technology news shocks by removing the forecastable variation in patents applications.

\subsection{Instrument Construction}

We recover an external instrument for the identification of technology news shocks as the component of quarterly utility patents applications that is orthogonal to agents' forecasts for the state of the economy, and is unpredictable given its own history. Intuitively, we seek to remove endogenous variation in applications filings that results from current or foreseen economic conditions.

Specifically, we recover an instrument for identification of news shocks using the residuals of the following regression, estimated at quarterly frequency

$$
p a_{t}=c+\gamma(L) p a_{t}+\sum_{h=1,4} \beta_{h} \mathbb{E}_{t}\left[x_{t+h}\right]+z_{t}
$$

$p a_{t}$ is the quarterly growth rate of all utility patent applications in a given quarter $t$, 
Table II: Dependence of Instrument on Economic Forecasts

\begin{tabular}{lccc}
\hline & $\mathbb{E}_{t}\left[w_{t}\right]$ & $\mathbb{E}_{t}\left[w_{t+1}\right]$ & $\mathbb{E}_{t}\left[w_{t+4}\right]$ \\
\cline { 2 - 4 } Wald Test & 0.270 & 0.850 & 0.290 \\
p-value & 0.949 & 0.531 & 0.882 \\
Adj $\mathrm{R}^{2}$ & 0.582 & 0.587 & 0.583 \\
$\mathrm{~N}$ & 127 & 127 & 127 \\
\hline
\end{tabular}

Notes: Dependent variable is the residual of Eq. (1). $\mathbb{E}_{t}\left[w_{t+h}\right]$ denotes SPF forecast published in quarter $t$. The forecast horizon is expressed in quarters. $w_{t}$ contains forecasts for real output growth, the unemployment rate, inflation (GDP deflator), real federal government spending, real non-residential investments, and real corporate profits net of taxes. Numbers reported are Wald test statistics for joint significance of the SPF forecasts at each horizon. All the regressions include own 4 lags, regulation dummy and constant. ${ }^{*}, * *, * *$ denote statistical significance at 10,5 , and $1 \%$ respectively.

\section{Table III: Dependence of Instrument on Lagged States}

\begin{tabular}{lccccccc}
\hline & $F_{1}$ & $F_{2}$ & $F_{3}$ & $F_{4}$ & $F_{5}$ & $F_{6}$ & $F_{7}$ \\
\cline { 2 - 8 } Wald Test & 0.880 & 1.160 & 0.290 & 0.810 & 1.040 & 0.190 & 0.290 \\
p-value & 0.481 & 0.330 & 0.882 & 0.521 & 0.389 & 0.945 & 0.885 \\
\cline { 2 - 7 } Adj R & 0.583 & 0.584 & 0.583 & 0.587 & 0.596 & 0.580 & 0.582 \\
$\mathrm{~N}$ & 127 & 127 & 127 & 127 & 127 & 127 & 127 \\
\hline
\end{tabular}

Notes: Dependent variable is the residual of Eq. (1). $F_{t}$ are factors extracted from the quarterly dataset of McCracken and $\mathrm{Ng}$ (2015). Numbers reported are Wald test statistics for the joint significance of the first 4 lags of each factor. All the regressions include own 4 lags, regulation dummy and constant. *, **, $* * *$ denote statistical significance at 10,5 , and $1 \%$ respectively.

i.e. $p a_{t}=100 \times\left(\ln P A_{t}-\ln P A_{t-1}\right)$. We exclude both 'missing' and 'not classified' patents applications from the count. $\gamma(L)=\sum_{j=1}^{4} \gamma_{j} L^{j}$, and $\mathbb{E}_{t}\left[x_{t+h}\right]$ is an $m \times 1$ vector of forecasts compiled at $t$ for the vector of economic variables $x_{t+h}$, where $h$ is equal to one and four quarters. We use median forecasts from the SPF to capture expectations about the state of the economy that may influence the decision of filing a patent application in a specific quarter $t$. The vector $x_{t}$ contains the unemployment rate $\left(u_{t}\right)$, inflation $\left(\pi_{t}\right)$, and the growth rates of real non-residential fixed investments $\left(I_{t}\right)$, and of real corporate profits after tax $\left(\Pi_{t}\right) . \forall t x_{t} \subset w_{t}$ used in Table I.

The procedure in Eq. (1) removes by construction both the autocorrelation in patent data, and the dependence on macroeconomic conditions as captured by the survey forecasts. In Tables III and II we check for correlation of the recovered instrument both with 
other forecasts at different horizons (i.e. $\mathbb{E}_{t}\left[w_{t+h}\right]$ ), and with the same factors of Table C.I. In both cases, we do not find evidence against the null of no correlation (i.e. the null that the instrument is Granger caused by the variables in the tables).

A final concern may relate to the potential correlation of patent application filings with other shocks occurring in the current quarter. In order to account for this, we augment Eq. (1) with a set of further controls intended to capture policy changes in the current quarter as follows

$$
p a_{t}=c+\gamma(L) p a_{t}+\sum_{h=1,4} \beta_{h} \mathbb{E}_{t}\left[x_{t+h}\right]+\delta s_{t}+z_{t}
$$

$s_{t}$ in Eq. (1') includes the current value and first two lags of unexpected and anticipated exogenous tax changes occurring at quarter $t$, as classified by Romer and Romer (2010) and Mertens and Ravn (2012), and the series of unanticipated changes to the intended Fed funds rate target of Romer and Romer (2004). ${ }^{13}$

The variables $p a_{t}$ and $z_{t}$ are plotted in Figure II. The grey dash-dotted line is the quarterly growth rate of patents applications $p a_{t}$. The green dash-dotted line are the residuals of Eq. (1) where there is no control for current and lagged policy changes. The solid blue line are the residuals of Eq. (1'). Due to the availability of the narrative tax series, the latter is available only up to 2006-IV. We use this as our preferred instrument. However, we also evaluate results obtained using the series which does not control for contemporaneous policy changes (green) as a potential instrument. Results are largely equivalent and discussed in Section 4.

\footnotetext{
${ }^{13} \mathrm{We}$ use the series of narrative changes in monetary policy extended to 2007 in Miranda-Agrippino and Rey (2015). Controlling for the changes in tax policy follows from the intuition in Uhlig (2004) who noted that changes in capital income taxes would lead to permanent effects on labor productivity and hence be a confounding factor in the analysis of technology shocks. This intuition was further developed in Mertens and Ravn (2011).
} 


\section{Identification of Technology News Shocks: Assump- tions and Challenges}

In the news literature, it is common to think of the process for technology as a random walk with drift subject to two stochastic disturbances

$$
\ln A_{t}=\Delta \ln A+\ln A_{t-1}+e_{\mathrm{A} 1, t}+e_{\mathrm{A} 2, t-k},
$$

where $\Delta \ln A$ is the steady state growth rate of technology, and $e_{\mathrm{A} 1, t}$ and $e_{\mathrm{A} 2, t-k}$ are zeromean normally distributed i.i.d. processes with variance equal to $\sigma_{\mathrm{A} 1}^{2}$ and $\sigma_{\mathrm{A} 2}^{2}$ respectively. $A_{t}$ is typically understood as a shifter to the aggregate production function of the economy, and intended to capture a concept of technology related to the efficiency with which the factors of production are utilized. ${ }^{14}$ In the reminder of the paper, we use a broader definition of technology that may refer to both the efficiency of inputs utilization, and the introduction of new processes altogether.

$e_{\mathrm{A} 2, t}$ is the news shock. ${ }^{15,16}$ The standard identifying assumption in the news literature is that agents learn about $e_{\mathrm{A} 2, t-k}$ before it hits the technology process, i.e. $k>0$ (see e.g. Beaudry and Portier, 2006; Barsky and Sims, 2011, among many others). However, a

${ }^{14}$ The aggregate production function can be though of as having the general form

$$
Y_{t}=f\left(E_{t} L_{t}, U_{t} K_{t}, A_{t}\right),
$$

where $Y_{t}$ is output, $E_{t}$ and $L_{t}$ denote labor effort and labor input respectively, $U_{t}$ is capital utilization, $K_{t}$ is the stock of installed capital, and $A_{t}$ is technology.

${ }^{15} \mathrm{An}$ alternative equivalent formalization assumes technology to be the sum of a stationary and a permanent component, with news shocks affecting the latter (see e.g. Blanchard et al., 2013; Kurmann and Sims, 2017).

${ }^{16}$ Chahrour and Jurado (2018b) show that any model with news such as that in Eq. (2) admits an observationally equivalent noise representation where the fundamental variable $\left(\ln A_{t}\right)$ is i.i.d. and agents receive a noisy signal about it $k$ periods into the future. In its simplest form, and with $k=1$, Eq. (2) reduces to

$$
\ln A_{t}=e_{\mathrm{A} 1, t}+e_{\mathrm{A} 2, t-1}, \quad\left(\begin{array}{c}
e_{\mathrm{A} 1, t} \\
e_{\mathrm{A} 2, t}
\end{array}\right) \sim \text { i.i.d. } \mathcal{N}\left(0,\left(\begin{array}{cc}
\sigma_{\mathrm{A} 1}^{2} & 0 \\
0 & \sigma_{\mathrm{A} 2}^{2}
\end{array}\right)\right)
$$

The associated noise representation is

$$
s_{t}=\ln A_{t+1}+\nu_{t}, \quad\left(\begin{array}{c}
\ln A_{t+1} \\
\nu_{t}
\end{array}\right) \sim \text { i.i.d. } \mathcal{N}\left(0,\left(\begin{array}{cc}
\sigma_{\mathrm{A}}^{2} & 0 \\
0 & \sigma_{\nu}^{2}
\end{array}\right)\right) .
$$

With full history of both fundamentals and beliefs about them being observable to the econometrician, the news and noise representations are observationally equivalent iff $(i) \sigma_{\mathrm{A}}^{2}=\sigma_{\mathrm{A} 1}^{2}+\sigma_{\mathrm{A} 2}^{2}$; and (ii) $\sigma_{\nu}^{2} / \sigma_{\mathrm{A}}^{2}=\sigma_{\mathrm{A} 1}^{2} / \sigma_{\mathrm{A} 2}^{2}$ (see Chahrour and Jurado, 2018b). 
number of more recent papers have argued that a news shock is also in principle compatible with $k=0$, which would affect technology also on impact (see e.g. Barsky et al., 2015; Kurmann and Sims, 2017). This may happen because news about future productivity arrives along with an innovation in current technology, because innovations to current technology may signal significant improvements in the following years, or because technology slowly diffuses across sectors. We subscribe to this interpretation, hence, empirically, we do not constrain news shocks to be orthogonal to the current level of technology. Allowing for $k=0$ naturally makes the task of telling apart a news shock with effects on current technology from an innovation in current technology a daunting one. In this respect, we rely on the information content of the instrument constructed in Section 2. As discussed, while patent applications are most informative for future technological changes $(k>0)$, the fact that innovations can be distributed under a patent-pending status does not rule out the $k=0$ case a priori. Hence, the use of the patent-based external instrument does not warrant imposing orthogonality with respect to the current level of technology. However, as we shall see in Section 4, while no assumption on the impact responses is made, the instrument recovers a shock which leads to an effectively muted response of total factor productivity (TFP) upon realization, while eliciting a strong and sustained response at further ahead horizons. This gives us some confidence that the recovered shock has a large element of news embedded in it.

We use our patent-based external instrument to back out the dynamic causal effects of a technology news shock on a collection of macroeconomic and financial variables in a structural Vector Autoregression (SVAR-IV, Mertens and Ravn, 2013; Stock and Watson, $2012,2018)$. In what follows, we discuss the common challenges to the identification of news shocks in Structural VARs, and the assumptions we make to achieve identification in our SVAR-IV.

Let $y_{t}$ denote the $n$-dimensional vector of economic variables of interest, whose dynamics follows a $\operatorname{VAR}(\mathrm{p})$

$$
\Phi(L) y_{t}=u_{t}, \quad u_{t} \sim \mathcal{W N}(0, \Sigma)
$$

where $\Phi(L) \equiv \mathbb{I}_{n}-\sum_{j=1}^{p} \Phi_{j} L^{j}, L$ is the lag operator, $\Phi_{j} j=1, \ldots, p$ are conformable matrices 
of autoregressive coefficients, and $u_{t}$ is a vector of zero-mean innovations, or one-stepahead forecast errors, i.e. $u_{t} \equiv y_{t}-\operatorname{Proj}\left(y_{t} \mid y_{t-1}, y_{t-2}, \ldots\right)$. We abstract from deterministic terms for notational brevity. Suppose we can write for $y_{t}$ the following structural VAR

$$
B(L) y_{t}=B_{0} e_{t}, \quad e_{t} \sim \mathcal{W N}\left(0, \mathbb{I}_{n}\right),
$$

where $B(L) \equiv \mathbb{I}_{n}-\sum_{j=1}^{p} B_{j} L^{j}, e_{t}$ is a vector of $n$ structural shocks with economic interpretation, and $B_{0}$ contains the contemporaneous transmission coefficients that characterize the effects of $e_{t}$ on $y_{t}$. Under full invertibility,

$$
u_{t}=B_{0} Q e_{t}
$$

where $Q$ is an orthogonal matrix. Hence, provided a set of suitable identifying restrictions (i.e. a choice for the rotation matrix $Q$ ), it is possible to recover the structural shocks from the VAR innovations $u_{t}$ by noting that $\Sigma=\mathbb{E}\left[u_{t} u_{t}^{\prime}\right]=B_{0} Q \mathbb{E}\left[e_{t} e_{t}^{\prime}\right] Q^{\prime} B_{0}^{\prime}=B_{0} B_{0}^{\prime}$. Full invertibility requires that in the structural MA representation of $y_{t}$ (i.e. its data generating process)

$$
y_{t}=C(L) e_{t},
$$

the polynomial $C(L)$ is invertible in non-negative powers of $L$, for which a necessary condition is that the roots of $\operatorname{det}(C(\zeta))$ all lie outside the unit circle, i.e. $\operatorname{det}(C(\zeta)) \neq$ $0 \forall \zeta=\varsigma_{i}:\left|\varsigma_{i}\right|<1$. If this condition is satisfied, then $e_{t}$ can be recovered from current and past observations of $y_{t}, y_{t}$ admits the representation in Eq. (7), and $e_{t}$ are $y_{t}-$ fundamental. If at least one root is inside the unit circle, then the process is not invertible, or invertible in the future. Because in this case the polynomial is invertible in negative powers of $L$, recoverability of $e_{t}$ requires knowledge of future $y_{t}, e_{t}$ are said to be $y_{t}$-non-fundamental, and cannot be recovered from a VAR. ${ }^{17,18}$

Non-fundamentalness is likely to arise when, as in the case of technology news shocks,

\footnotetext{
${ }^{17}$ Early treatments of non-fundamentalness are in e.g. Hansen and Sargent (1980, 1991); Lippi and Reichlin (1993, 1994). Fernández-Villaverde et al. (2007) provide the 'Poor Man's Invertibility Condition' for the mapping between the state space representations of DSGEs and VARs.

${ }^{18}$ Here we intend that the shocks cannot be recovered from knowledge of $y_{t}$ and its lags only. For a broader discussion on shocks recoverability, and how it relates to the invertibility concept reviewed here see Chahrour and Jurado (2018a).
} 
agents anticipate future changes (see e.g. Leeper et al., 2013). If news shocks only affect current TFP with delay (i.e. $k>0$ ), then current TFP only conveys information about past news shocks. Using forward looking variables, such as e.g. the stock market index, can help, but is not guaranteed to resolve the issue. This is the case, for example, in the bivariate VAR of Beaudry and Portier (2006), as discussed in Kurmann and Mertens (2014) and Forni et al. (2014).

While the issue of non-fundamentalness is a theoretically binding constraint for the usefulness of empirical VARs, Sims (2012b) shows that, empirically, it should not be thought of as an 'either/or' problem. Even with non-invertibility, the 'wedge' between the shocks estimated in a structural VAR and the theoretical ones may be small enough that VAR-based inference may still deliver accurate results, in the form of impulse response functions (IRFs) to the identified shocks. ${ }^{19}$ In the context of technology news shocks, the issue arises because, due to anticipation, news shocks also become state variables that agents need to keep track of when solving their equilibrium problem. However, these being unobservable, they cannot be conditioned upon, and the problem essentially becomes one of missing information: the observables are insufficient to reveal the true states. Furthermore, the longer the anticipation lag $(k)$, the larger is the number of additional unobserved states, the more severe the information insufficiency is likely to be, and the higher the risk that VARs will lead to misleading inference (see Sims, 2012b). Hence, in this context, a natural route towards the problem solution is to add information to the VAR, through variables that help forecasting the states. This is the role of e.g. the stock price index in Beaudry and Portier (2006), or measures of consumers or business confidence as in Barsky and Sims (2012). In a similar vein, factors estimated from large cross-sections can be added to the VAR specification as in e.g. Giannone and Reichlin (2006); Forni and Gambetti (2011).

In our framework, we focus only on a subset of the structural shocks, in particular, on the sub-vector $e_{\mathrm{A}, t}$ of $e_{t}$ containing the shocks specific to the technology process $A_{t}$. Hence, for our purpose, we require that the information in the VAR be sufficient for the identification of $e_{\mathrm{A}, t}$ only, which is a less stringent assumption than full invertibility.

\footnotetext{
${ }^{19}$ This point is further discussed in Beaudry and Portier (2014); Beaudry et al. (2015, 2016).
} 
Specifically, we assume that there exists a $1 \times n$ vector $\lambda$ such that

$$
e_{\mathrm{A}, t}=\lambda u_{t},
$$

or, in other words, that there exists a suitable rotation of the VAR innovations that reveals the shock of interest $e_{\mathrm{A}, t}$. Forni et al. (2018) and Miranda-Agrippino and Ricco (2018) show that in cases in which full invertibility is not attained, and conditional on a correct identification scheme, the estimated IRFs to the shock of interest converge to the 'true' ones, provided that Eq. (10) holds. Miranda-Agrippino and Ricco (2018) discuss in particular the conditions required for identification with external instruments in SVAR-IVs under partial invertibility. Let $z_{t}$ denote the external instrument used for the identification of $e_{\mathrm{A}, t}$. The required conditions are:

$$
\begin{array}{ll}
\mathbb{E}\left[e_{\mathrm{A}, t} z_{t}^{\prime}\right]=\rho, \rho \neq 0 & \text { (Relevance) } \\
\mathbb{E}\left[e_{i, t} z_{t}^{\prime}\right]=0, \forall i \neq A & \text { (Contemporaneous Exogeneity) } \\
\mathbb{E}\left[e_{i, t+\tau} z_{t}^{\prime}\right]=0, \forall i \neq A, \tau \neq 0: \mathbb{E}\left[e_{i, t+\tau} u_{t}^{\prime}\right] \neq 0 . & \text { (Limited Lag Exogeneity) }
\end{array}
$$

Under these conditions, the impact responses to $e_{\mathrm{A}, t}$ of all variables in $y_{t}$ are consistently estimated (up to scale and sign) from the projection of the VAR innovations $\hat{u}_{t}$ onto the instrument $z_{t}$ (Mertens and Ravn, 2013; Stock and Watson, 2012, 2018). ${ }^{20}$ The first two conditions are the standard conditions for instruments validity in IV identification. The third condition arises because of the dynamics, and essentially requires that the instrument and the VAR innovations are only related via the shock of interest, hence allowing the instrument to be potentially contaminated by leads or lags of other shocks, so long as these are 'filtered out' by the VAR. Hence, with a potentially imperfect instrument, these conditions call for the use of rich-information VARs which make Condition (13) a

\footnotetext{
${ }^{20}$ The procedure boils down to the following steps. 1. Estimate $\hat{u}_{t}$ from a VAR(p) in $y_{t} ; 2$. Estimate the coefficients of interest (i.e. the relevant column $\mathrm{b}_{0}$ of $B_{0}$ ) from a regression of $\hat{u}_{t}$ on $z_{t}$ by noting that $\rho \mathrm{b}_{0}=\mathbb{E}\left[u_{t} z_{t}^{\prime}\right] ; 3$. Normalize entries in $\hat{\mathrm{b}}_{0}$ (see Mertens and Ravn, 2013). It is worth highlighting that the samples of Step 1 and 2 do not need to coincide. In Section 4 we refer to the sample used for Step 1 as the estimation sample, and the one used for Step 2 as the identification sample respectively. Stock and Watson (2018) suggest an alternative procedure to address the issue of $\hat{u}_{t}$ being a generated regressor in Step 2 above. In our case, the two procedures are equivalent since $z_{t}$ is uncorrelated with lagged state variables (see Table III) and hence with lagged $y_{t}$.
} 
more plausible one. Furthermore, Forni et al. (2018) show that if the VAR is informationally sufficient for $e_{\mathrm{A}, t}$ but not for the other shocks, then the forecast error variance contribution of $e_{\mathrm{A}, t}$ is underestimated.

Given these considerations, and because both the dynamic responses and the relative contribution of news shocks to economic fluctuations are of interest, we base our discussion on a rich-information VAR whose heterogeneous entries are intended to both cover the relevant variables that are of interest, and capture possible anticipation of future events that is at the core of the transmission mechanism of news shocks.

\section{Results: News Shocks and Business Cycle}

In this section, we describe our empirical results in the form of impulse response functions to the news shock identified using the instrument of Section 2. A broader discussion against the different transmission mechanisms and models that have been proposed in the literature is reported in Section 5.

We study the transmission and importance of technology news shocks in a 16-variable quarterly VAR that includes a rich and heterogeneous set of variables. These are all listed in Table A.I in the appendix, and include TFP, output and its components, labour market data, prices and wages, as well as asset prices and measures of consumers' expectations. Appendix A also provides a detailed description of our dataset and of the construction of the variables used. Variables enter the VAR in log levels, with the exception of interest rates and corporate spreads, and are deflated and expressed in per-capita terms where appropriate (see Table A.I). We use the GDP deflator to measure inflation. The VAR is estimated with 4 lags and standard Normal-Inverse Wishart priors (Doan et al., 1983; Litterman, 1986; Kadiyala and Karlsson, 1997). The optimal priors' tightness is estimated as in Giannone et al. (2015). Minor perturbations to the number of lags included do not change the results. ${ }^{21}$ The VAR(4) is informationally sufficient (Forni and Gambetti, 2011)..$^{22}$

\footnotetext{
${ }^{21}$ We address concerns in e.g. Canova et al. (2009) and Fève et al. (2009) by re-estimating our baseline VAR with 12 lags. The richer parametrization substantially increases the computational burden but does not materially change our results. IRFs are not reported but available upon request.

${ }^{22}$ We use the multivariate test for informational sufficiency of Forni and Gambetti (2011) and do not find evidence of any of the lagged state variables Granger causing the VAR residuals. Quarterly factors
} 


\section{Figure III: The Slow Diffusion of TeChnology}

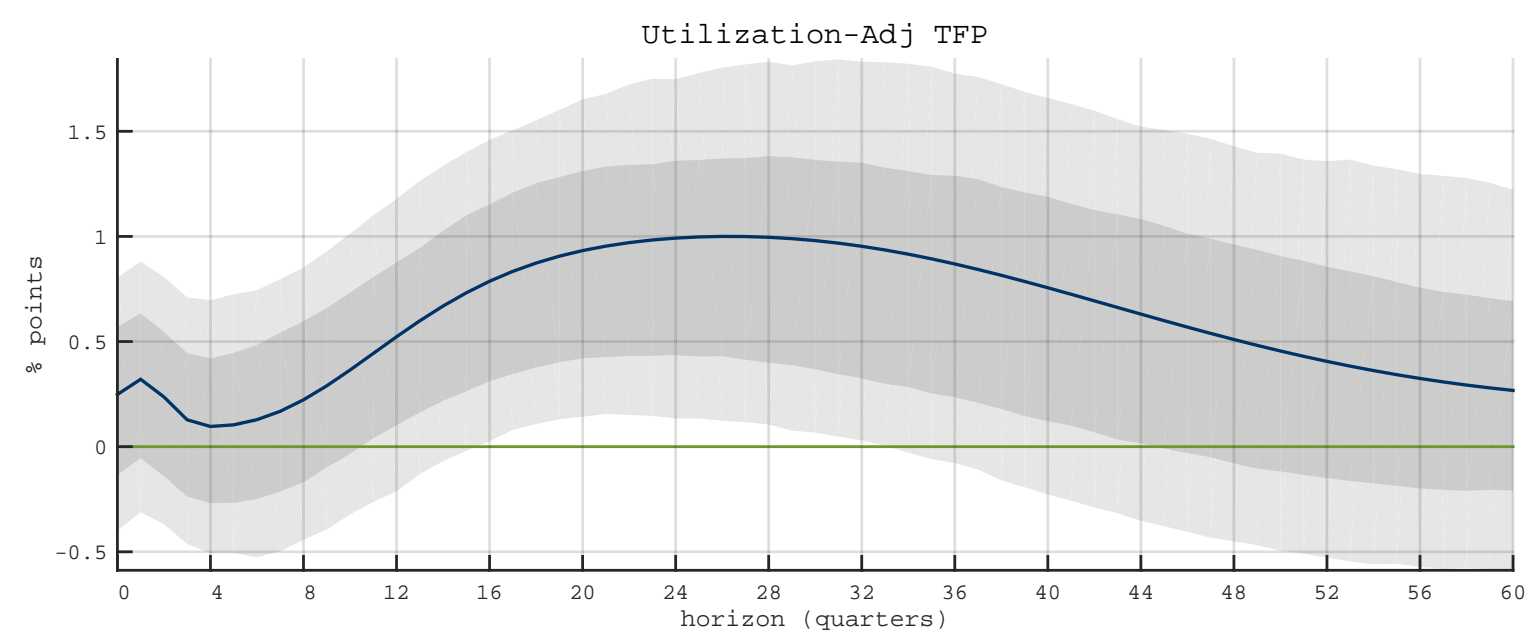

Note: Modal response of Utilization-Adjusted TFP to a technology news shock identified with patentsbased external instrument. VAR(4). Estimation sample 1971-I : 2016-IV. Identification sample 1982-I : 2006-IV. Shaded areas denote $68 \%$ and $90 \%$ posterior coverage bands.

Our benchmark estimation sample is 1971-I:2016-IV, where the starting date is constrained by the availability of the Nasdaq Composite stock market index, and of a quarterly series for capacity utilization. ${ }^{23}$ Our preferred specification uses the patent-based external instrument that also controls for contemporaneous policy changes, which gives us an identification sample running from 1982:I to 2006-IV. ${ }^{24}$ Robustness tests are discussed below and reported in Appendix D.

The impulse response functions (IRF) to a positive technology news shock are reported in Figures III to VII. These are IRFs at the mode of the posterior distribution of the parameters. $^{25}$ We discuss each in turn. The responses are scaled such that the peak response of TFP equals $1 \%$.

are extracted from the McCracken and $\mathrm{Ng}$ (2015) quarterly FRED dataset. The test statistic for the joint significance of the lagged state variables is equal to 198.9 against a critical value of 0.99.

${ }^{23}$ We prefer to work with the Nasdaq index since this is more directly linked to developments in the industrial sector than the S\&P 500. In fact, the latter also includes financial institutions including investment banks, and other entities such as insurance companies which can act as confounding elements, particularly in light of the financial crisis of late 2007-2008. We discuss results relative to the response of the S\&P 500 below.

${ }^{24}$ Figure D.IV in the Appendix compares it with responses obtained without directly controlling for contemporaneous policy changes (i.e. the green line in Figure II). Results are qualitatively the same, but estimated with a slightly larger degree of uncertainty. Error bands for both specifications are not reported for ease of readability, but available upon request.

${ }^{25}$ Median responses across the draws are virtually the same. 
Figure III plots the response of TFP to the identified technology news shock over a period of 60 quarters. We use the quarterly series of total factor productivity corrected for input utilization of Fernald (2014). TFP rises mildly on impact, then contracts slightly, and finally returns to trend following a persistent hump that reaches a peak between 6 and 7 years after the shock. The response is not significant for the first two years. The shape of the TFP response resembles the S-shaped pattern that is typical of the slow diffusion of new technologies documented, among others, in Griliches (1957); Mansfield (1961); Rogers (1962) and Gort and Klepper (1982). Technology diffuses slowly at first. This initial phase is then followed by a fast diffusion period that ends once the new technology has been fully absorbed, and diffusion reaches its maximum. A similarly shaped response is reported in Barsky et al. (2015) and Kurmann and Sims (2017). Both these papers identify technology news shocks based on the forecast error variance of TFP, and do not restrict the impact response of TFP to be zero. ${ }^{26}$

The responses of the variables related to economic activity are reported in Figure IV. Consumption rises immediately following the shock, and remains elevated throughout, to return to trend only after about 5 years. Output, investment, and capacity utilization stay mostly put on impact, and then rise persistently to reach a peak after about two years after the shock hits. Impact modal responses are negative, but only marginally significant at conventional levels, and fully reabsorbed in the span of two to three quarters. The magnitude of the responses is economically important. Output reaches half a percentage point at peak, while investment increases by $1.5 \%$. The labor market witnesses similarly significant improvements at the two year horizon. Here, however, we note that the initial decline in labor inputs, albeit short-lived, is strongly significant, and more robust to changes to either the sample size or the VAR specification than the other negative impact responses of Figure IV. R\&D expenditures (as a component of output) do not seem to respond to the shock in significant ways. While modal reactions suggest R\&D to be somewhat higher following the shock, the response is only significant at the two-year horizon. This could be entirely driven by the rise in output.

\footnotetext{
${ }^{26}$ Kurmann and Sims (2017) consider the case in which TFP measures true technology with an error that correlates with economic conditions. Assuming that the measurement error albeit systematic is nevertheless transient, identification based on the long-run forecast error variance of TFP avoids reliance on its short term fluctuations, and is thus robust to such mis-measurements.
} 


\section{Figure IV: QuANTITIES}
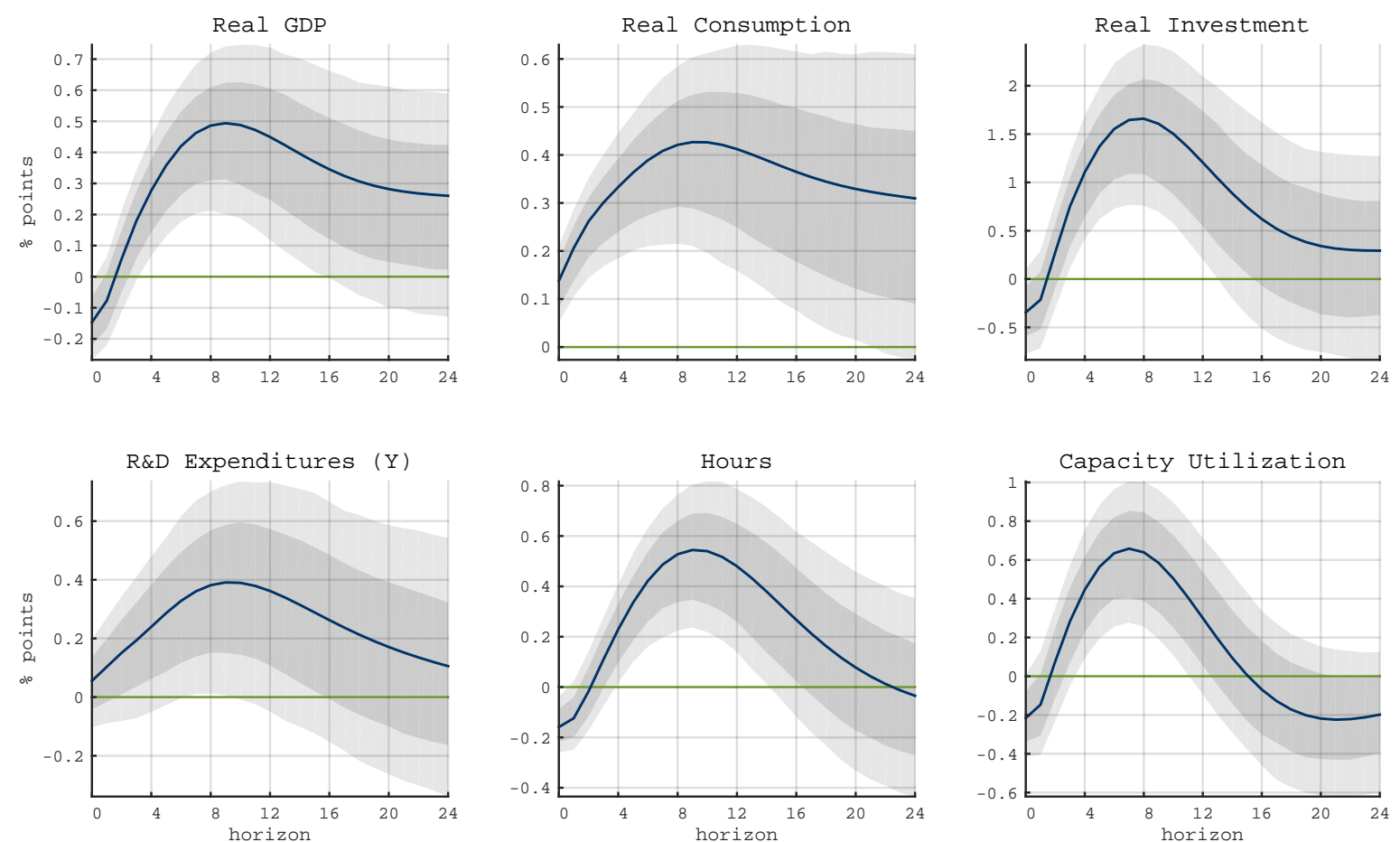

Note: Modal response of quantities to a technology news shock identified with patents-based external instrument. VAR(4). Estimation sample 1971-I : 2016-IV. Identification sample 1982-I : 2006-IV. Shaded areas denote $68 \%$ and $90 \%$ posterior coverage bands.

Hence, the identified technology news shock can induce comovements among variables that are typical of business cycle fluctuations over medium horizons, but does not seem to do so on impact. In this respect, our findings align with some of the results in e.g. Francis and Ramey (2005); Basu et al. (2006) and Barsky and Sims (2011), although the responses in Figure IV (and with the exception of hours worked) point towards a muted initial response of real activity, rather than a fully recessionary episode. The timing of the responses in Figures III and IV does lend credit to a 'news view' in the spirit of what described in e.g. Beaudry and Portier (2006); Beaudry and Lucke (2010), to the extent that the movements in the quantity variables substantially anticipate the actual increase in TFP. Hence, there seems to be evidence in favor of news triggering business cycle-type fluctuations before any significant change in technology is effectively realized.

The shock, however, is not the main driver of fluctuations in economic variables at 


\section{Figure V: Shares of Explained VARiance}
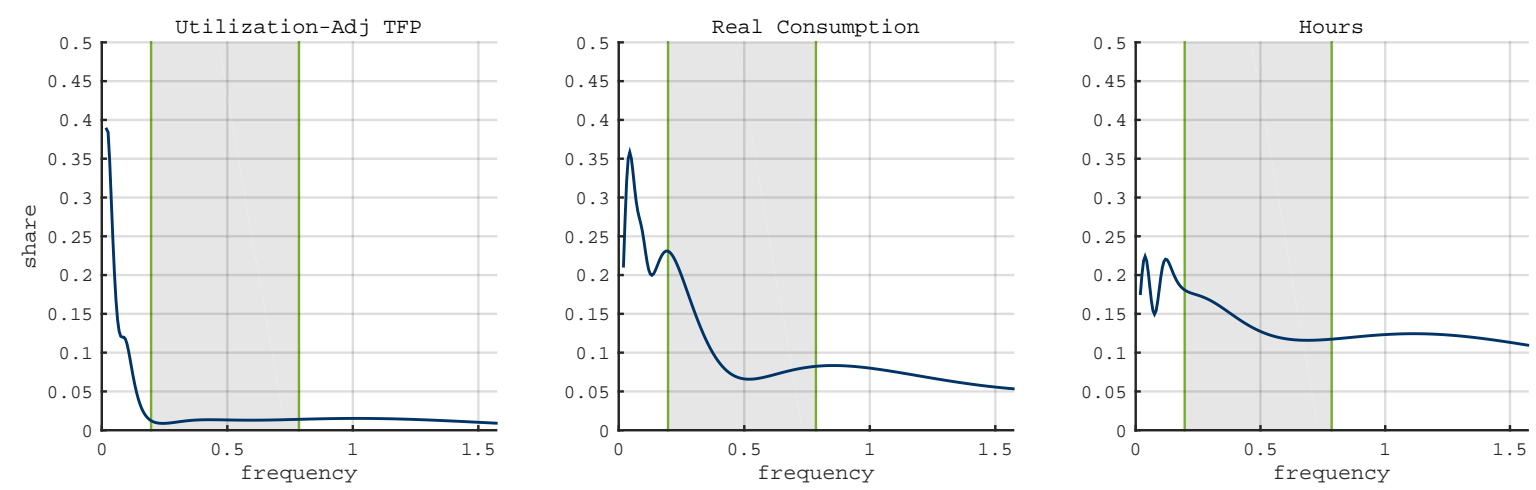

Note: Share of error variance accounted for by technology news shock identified with patents-based external instrument. VAR(4). Estimation sample 1971-I : 2016-IV. Identification sample 1982-I : 2006IV. Shaded areas delimits business cycle frequencies (between 8 and 32 quarters). Frequencies on the $x$ axis cover a period from 1 (highest) to 100 (lowest) years.

business cycle frequencies. Figure V plots the share of variance of TFP, consumption, and hours that is accounted for by the identified technology news shock at all frequencies between 1 (highest frequency) and 100 (lowest frequency) years. ${ }^{27}$ The algorithm used for the decomposition builds on Altig et al. (2011), and is described in detail in Appendix B. ${ }^{28}$ The identified shock explains at most $40 \%$ of the variation of TFP in the very long run (100 years). Table IV reports the shares of explained variation at selected frequency intervals for all variables. The recovered news shock is responsible for virtually none of the variation in TFP either in the short-run (i.e. area under the curve in rightmost section of the left panel of Figure V, corresponding to a period of 1 to 2 years), or at business cycle frequencies ( 2 to 8 years), and accounts for about $10 \%$ of its variation in the long-run ( 8 to 25 years, see Table IV). At the same time, it is responsible for about $16 \%$ of the fluctuations in both consumption and hours at business cycle frequencies, and accounts for over a quarter of the variation in consumption, and about a fifth of that in labor inputs in the long-run. These shares are sizeable and economically relevant, but far from capturing the bulk of variation in these variables.

\footnotetext{
${ }^{27}$ Recall $\omega=2 \pi / t$, where $t$ denotes time and $\omega$ denotes the frequency. A period of 1 year (4 quarters) corresponds to $\omega \simeq 1.57$, while 100 years yield $\omega \simeq 0.02$. Business cycle frequencies, typically set between 8 and 32 quarters, correspond to frequencies between [0.2 0.8$]$.

${ }^{28}$ We discuss the contribution of the news shock to fluctuations in the remaining variables in our VAR at the end of this section (see Table IV). Variance decompositions for all variables at all frequencies between 1 and 100 years are in Figure B.I in the Appendix.
} 


\section{Figure VI: Prices \& WAGES}
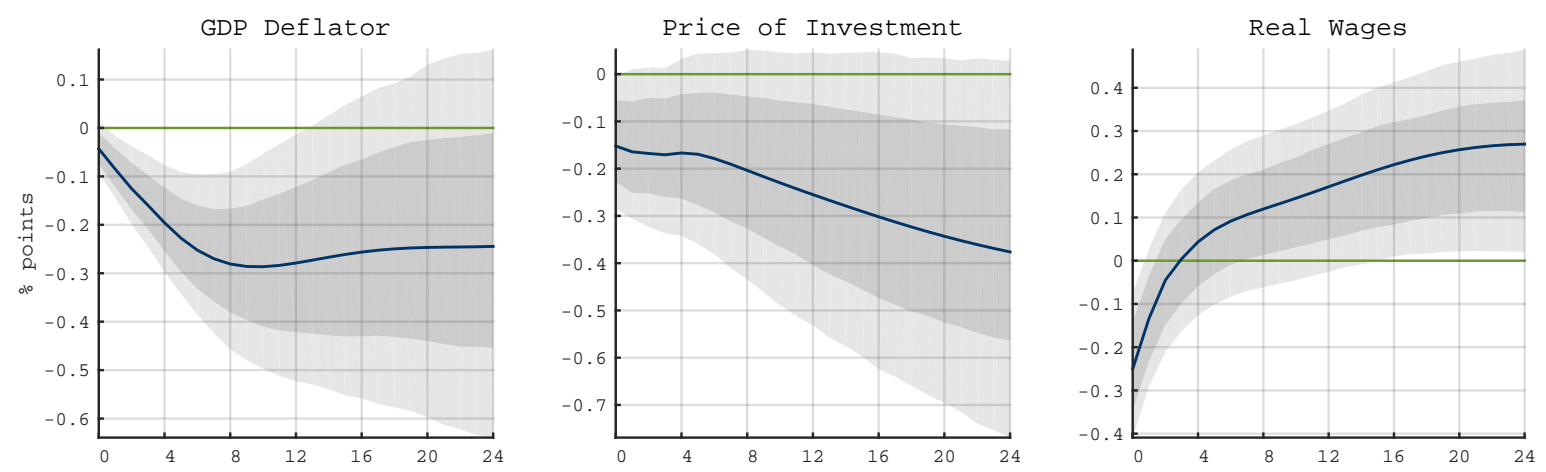

Note: Modal response of price variables to a technology news shock identified with patents-based external instrument. VAR(4). Estimation sample 1971-I : 2016-IV. Identification sample 1982-I : 2006-IV. Shaded areas denote $68 \%$ and $90 \%$ posterior coverage bands.

The responses of prices are reported in Figure VI. Similarly to what is found in Barsky and Sims (2011); Kurmann and Otrok (2013) and Barsky et al. (2015), we find that technology news shocks are disinflationary. Importantly, however, while these authors document a sudden and persistent drop, we unveil a rather inertial response of prices upon realization of the shock. The GDP deflator contracts only marginally on impact, but keeps sliding over the subsequent quarters, reaching a peak response of about $-0.3 \%$ at the two year horizon, consistent with a sluggish adjustment of prices over time. A similarly sluggish adjustment is characteristic of the relative price of investment goods. While the response is estimated with a substantial degree of uncertainty, it seems to suggest that the identified news shock makes investment goods cheaper relative to consumption goods. Hence, the shock has some of the flavor of the investment-specific technology improvements of e.g. Fisher (2006), Justiniano et al. (2010, 2011), Ben Zeev and Khan (2015) and Ben Zeev (2018). Figure VI also reports the response of real wages. We find that wages significantly contract on impact, to increase at longer horizons. We discuss the response of wages in greater detail in the next section.

Lastly, we collect responses of asset prices and measures of consumers' expectations in Figure VII. The stock market prices the news shock strongly and significantly on impact - the Nasdaq index jumps up by $6 \%$ upon realization of the shock. The strong response of the stock market is more notable when the Nasdaq is used, due to the index com- 

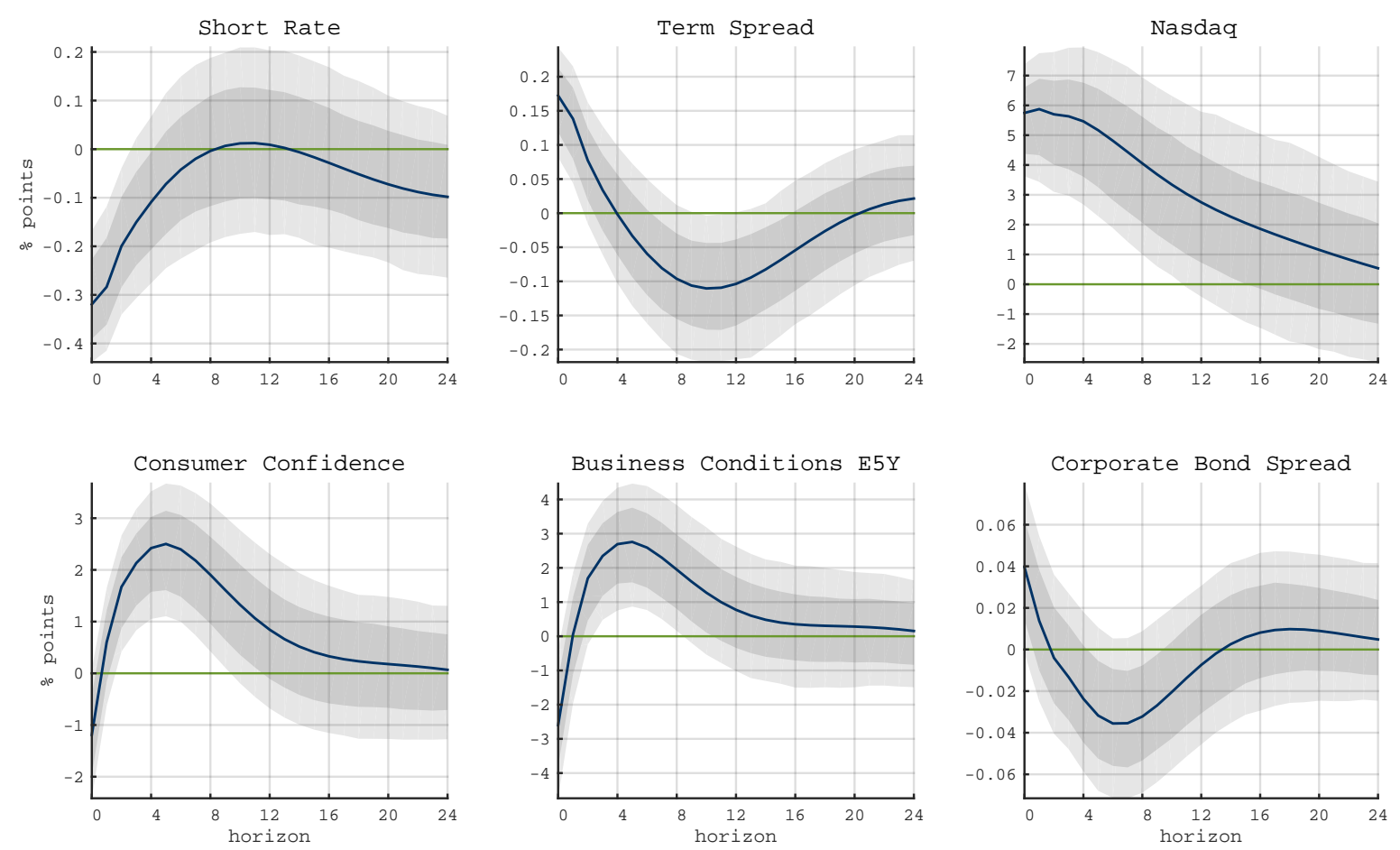

Note: Modal response of consumers' expectations and financial markets to a technology news shock identified with patents-based external instrument. VAR(4). Estimation sample 1971-I : 2016-IV. Identification sample 1982-I : 2006-IV. Shaded areas denote $68 \%$ and $90 \%$ posterior coverage bands.

position being heavily weighted towards information-technology companies. These are presumably those mostly affected by these types of shocks over the identification sample considered (1982-I:2006-IV). Figure D.II in the appendix compares IRFs in our benchmark sample with those obtained when estimating the VAR from 1962-I, and substituting the Nasdaq Composite with the S\&P 500 (same identification sample). While the S\&P response is still positive on impact, the magnitude is about a third of that of the Nasdaq. ${ }^{29}$ Consistent with a world in which companies only slowly adjust to the introduction of new technologies, the BAA-AAA corporate bond spread slightly increases on impact, to improve at medium horizons. This response is however not strongly significant.

The significant disinflationary characteristic of the identified news shock induces an

\footnotetext{
${ }^{29}$ In this case we drop the capacity utilization variable which is unavailable prior to the 1970 s, and substitute the Nasdaq with the S\&P 500. The start date coincides with the availability of daily data for interest rates (DGS1 and DGS10) that enter the VAR in quarterly averages.
} 
TABle IV: ERror VARIAnce Decomposition

\begin{tabular}{llccc}
\hline & & $\begin{array}{c}\text { SHORT RUN } \\
{[4-8 \text { quarters }]}\end{array}$ & $\begin{array}{c}\text { BUSINESS CYCLE } \\
{[8-32 \text { quarters }]}\end{array}$ & $\begin{array}{c}\text { LONG RUN } \\
{[32-100 \text { quarters }]}\end{array}$ \\
\cline { 3 - 5 } TFPL & Utilization-Adj TFP & 1.39 & 1.17 & 10.20 \\
RGDP & Real GDP & 10.17 & 13.77 & 19.32 \\
RCONS & Real Consumption & 7.47 & 15.79 & 26.48 \\
RINV & Real Investment & 8.00 & 14.02 & 13.10 \\
RDGDP & R\&D Expenditures (Y) & 0.45 & 5.50 & 8.86 \\
HOURS & Hours & 12.07 & 16.36 & 17.83 \\
CAPUTIL & Capacity Utilization & 7.90 & 12.31 & 15.82 \\
GDPDEF & GDP Deflator & 2.28 & 9.81 & 14.44 \\
RPINV & Price of Investment & 3.27 & 2.19 & 7.64 \\
RWAGE & Real Wages & 8.29 & 4.29 & 12.91 \\
SHORTR & Short Rate & 15.90 & 10.28 & 2.20 \\
YCSLOPE & Term Spread & 13.57 & 12.09 & 6.20 \\
EQY2 & Nasdaq & 25.60 & 24.46 & 23.04 \\
CCONF & Consumer Confidence & 9.01 & 14.52 & 16.03 \\
BCE5Y & Business Conditions E5Y & 9.39 & 9.77 & 10.59 \\
CBSPREAD & Corporate Bond Spread & 2.95 & 5.16 & 2.64 \\
\hline
\end{tabular}

Notes: Share of error variance accounted for by the identified technology news shock over different frequency intervals. Numbers are percentage points. The algorithm used builds on Altig et al. (2011) and is detailed in Appendix B.

endogenous strong response of the monetary authority, that responds more than proportionally to the decline in inflation. Due to the sample considered including the zero-lowerbound (ZLB) period, we use the one year nominal interest rate as our measure for the short term policy rate. In Figure D.I we verify that neither the global financial crisis nor the ZLB sample drive or affect our results. The one year rate falls by 30 basis points on impact, which is roughly the same magnitude as the peak decline of prices (see Figure VI). This implies that shorter maturity interest rates are likely to fall by more, and hence that short-term real interest rates fall following the shock. The slope of the yield curve, here measured as the spread between the 10-year and the 1-year Treasury rates, rises by about 15 basis points on impact, mainly driven by changes at the short end, and implying a 15 bps fall in long term yields. Similar types of impact responses are reported in Kurmann and Otrok (2013), where the identified news shock is also responsible for most of the unexplained variation in the slope of the term structure of interest rate. We do 
not find this to be the case. Table IV shows that the shock is most explanatory over the short-run, where it can account for about $15 \%$ of movements in the term structure, but it captures virtually none of the variation in interest rates in the long run. The impact response of the short term rate also contrasts with findings in Kurmann and Sims (2017), where the response of the monetary authority is mildly contractionary. ${ }^{30}$

Finally, Figure VII reports responses of a consumer confidence indicator and a business confidence indicator reflecting expectations about economic conditions over a horizon of 5 years, both taken from the Michigan Survey of Consumers. Interestingly, we find that while both measures of confidence robustly rise at medium horizons, they do not do so on impact. In fact, the responses tend to be negative upon realization of the shock. This finding is consistent with agents overweighting the responses of current economic conditions discussed in Figure IV when forming their expectations about the future, and echoes the implications of models in which agents are subject to informational rigidities. We return to this issue in greater detail in the next section.

\section{Discussion of the Results: the Transmission of News about Future Technology}

Equipped with the empirical results reported in Section 4, in this section we try to shed some light on the likely transmission mechanisms by evaluating our findings against the different models proposed in the literature.

Total Factor Productivity As noted, the impulse response function of TFP to the identified news shock supports the hypothesis of slow diffusion of technology over time (see e.g. Rotemberg, 2003, and references therein). ${ }^{31}$ While there is evidence of some

\footnotetext{
${ }^{30}$ For a broader discussion on the role played by different vintages of TFP data on the response of the term structure slope to technology news shocks see Cascaldi-Garcia (2017); Kurmann and Otrok (2017).

${ }^{31}$ Among others, Rogers (1962); David (1990), and Hall (2006), have rejected the Real Business Cycle view according to which productivity jumps up immediately to its new (higher) steady state level following a technological shock, and have instead produced evidence that suggests a slow diffusion of technology. In particular, the diffusion process is well approximated by an S-shaped curve. While the slow diffusion of technology and its implications for the modeling of productivity is discussed extensively in e.g. Rotemberg (2003); Comin and Gertler (2006); Lindé (2009), much of the business cycle literature has modeled productivity as a jump process where innovations lead to an immediate change of productivity to a new level that is either permanent or highly persistent. Other papers that build models of
} 
(non-significant) positive spillover to current TFP, productivity does not materially move away from zero before the first 4 years after the shock hits. Hence, the effect of a news shock on current TFP is estimated to be effectively zero, even if we have not imposed such restriction ex ante. Moreover, by the time the TFP response becomes positive, and perhaps with the exception of real wages, the dynamics of all the other variables in the VAR are mostly exhausted, and all have comfortably returned back to trend. This large asynchronicity in the timing of the responses favors the hypothesis that macro aggregates can in fact move as a result of a change in expectations about future productivity growth, and before the change in aggregate technology materializes. The ensuing business cycle expansion is not estimated to be immediate, and we return to this point below. Hence, while it appears that business-cycle types of comovements can in fact be triggered, here we note that the relatively small share of explained variance that is accounted for by the identified news shock at business cycle frequencies casts substantial doubts on it being a main driver of economic fluctuations. ${ }^{32}$ Importantly, this also holds true for the TFP process itself. Our estimates suggest that technology news account at best for $40 \%$ of the variance of TFP at very low frequencies (see Figure V), which may potentially put into question identification schemes that rely on 'max share' of explained TFP variation at one or some long horizons (e.g. Barsky and Sims, 2011; Kurmann and Otrok, 2013; Francis et al., 2014; Forni et al., 2014; Barsky et al., 2015, among others).

Quantities: Output, Consumption, Investment, and Hours In our VAR output, investment, consumption and hours worked are all significantly higher a few quarters after the shock hits, with peak effects realized in the span of two years. On impact, consumption rises strongly, hours decline, and although modal responses are negative, investment and output do not meaningfully move away from zero before they start increasing. Capacity utilization also rises after staying still on impact. These types of responses are hard if not impossible to rationalize under the standard neoclassical real business cycle costly adoption of new technologies that are consistent with a slow diffusion pattern are e.g. Comin et al. (2009) and Comin and Hobijn (2010).

${ }^{32}$ Similar conclusions have been reached in a DSGE framework in e.g. Fujiwara et al. (2011); SchmittGrohé and Uribe (2012) and Khan and Tsoukalas (2012). Sims (2016) argues that empirical works may be confounding current and past news shocks, hence implying a potentially systematic overstatement of the relative importance of news shocks in earlier studies. 
(RBC) paradigm. The rise in consumption is understood to be the result of a wealth effect: expectations of future higher productivity raise expectations about future income, which in turn induce households to smooth consumption towards higher current levels. The same wealth effect also increases the desire for leisure, while higher expected future productivity redirects the capital stock away from investment and towards consumption until the higher productivity level is realized. Hence, consumption, labor effort and investment must in this case move in opposite directions (Barro and King, 1984; Cochrane, 1994). Moreover, in the classical RBC setting, a fixed labor demand implies that the fall in hours worked must come from a shift in the labor supply curve, which in turn requires an increase in wages. This too contrasts with our findings: real wages significantly contract upon realization of the shock, and only slowly increase over time.

We interpret the delayed business cycle expansion that is triggered by the news shock as indicative of the presence of potentially different sources of inertia that delay the adjustments. In fact, the responses of quantities documented here is consistent with New Keynesian models with nominal rigidities that influence the setting of prices, wages, or both (e.g. Barsky and Sims, 2009; Christiano et al., 2010; Barsky et al., 2015), and with $\mathrm{RBC}$ models augmented with real rigidities such as e.g. habit formation in consumption, and adjustment costs associated with changes in either the stock of capital or the rate of investment, and equipped with a system of preferences that allows to fine-tune the wealth elasticity of labor supply (e.g. Jaimovich and Rebelo, 2009; Schmitt-Grohé and Uribe, 2012). A weakened short-run wealth effect can in fact induce a right shift in the labor supply. At the same time, the presence of adjustment costs and variable capital utilization can induce positive shifts in labor demand if the price of capital decreases as a consequence of the shock. However, while these types of mechanisms can account for the positive comovements, they cannot reproduce other important effects, such as e.g. the increase in asset prices. In fact, these models predict that asset prices will move with the cost of capital, and will hence decrease (see e.g. Christiano et al., 2010). ${ }^{33}$

Prices: Inflation and Wages New Keynesian models with nominal rigidities, including those where such frictions arise endogenously due to imperfect common knowledge

\footnotetext{
${ }^{33}$ Business cycle comovements are also reproduced in standard RBC frameworks augmented with dispersed information (see e.g. Angeletos and La'O, 2010).
} 
(e.g. Mankiw and Reis, 2002; Woodford, 2003) seem to offer a more varied array of mechanisms through which our findings can be rationalized. This is because they allow the dynamics to be dominated by the demand side, at least in the short-run (see discussion in e.g. Lorenzoni, 2009, 2011). In the VAR, the shock triggers a sudden and marked contraction of real wages followed by a slow, but significant deflationary episode. Prices drop mildly on impact, and continue to slide over time to reach a peak contraction two years after the shock. Real wages eventually increase; the time taken for the wage inflationary pressure to materialize goes from 8 to 16 quarters depending on the chosen significance level. The deflationary effect of news shocks is a robust finding, and has been documented in Christiano et al. (2010); Jinnai (2013); Kurmann and Otrok (2014) and Barsky et al. (2015) among others. However, contrary to findings in e.g. Barsky and Sims (2009, 2012) and Kurmann and Otrok (2014), we find that the bulk of the drop in inflation is not realized on impact. Rather, and consistent with nominal rigidities preventing an immediate impact adjustment, the response of prices is subdued initially, and only slowly builds up over time. Christiano et al. (2010) and Barsky and Sims (2011) interpret the fall in prices as a manifestation of the forward-looking nature of inflation in the New Keynesian model, where current inflation is a function of both current and future expected marginal costs. As also discussed in Barsky et al. (2015), expected future productivity improvements lower expected real marginal costs. If real wages do not rise too sharply, the expectation that marginal costs will be lower in the future creates downward pressure on current inflation. Whether this happens in practice depends on the persistence of the news process, the monetary policy rule, and the potency of nominal rigidities. For a given news process, and leaving temporarily aside the role of the monetary authority, the fall in inflation following the news shocks can be obtained under two different specifications of nominal frictions: a case of pure sticky prices as in e.g. Calvo (1983), and one in which prices are flexible, but wages are staggered like in e.g. Erceg et al. (2000). Christiano et al. (2010) show that while both scenarios give rise to a deflation, the range of parameters across which this happens in a sticky wage environment is larger. Consider first the case of price stickiness. Positive news about future productivity set out the expectation that prices will be lower also for those on the demand side of the labor market. Most of this effect, however, is expected to be realized in the future, due to the presence of 


\section{Figure ViII: Long Rate Response}

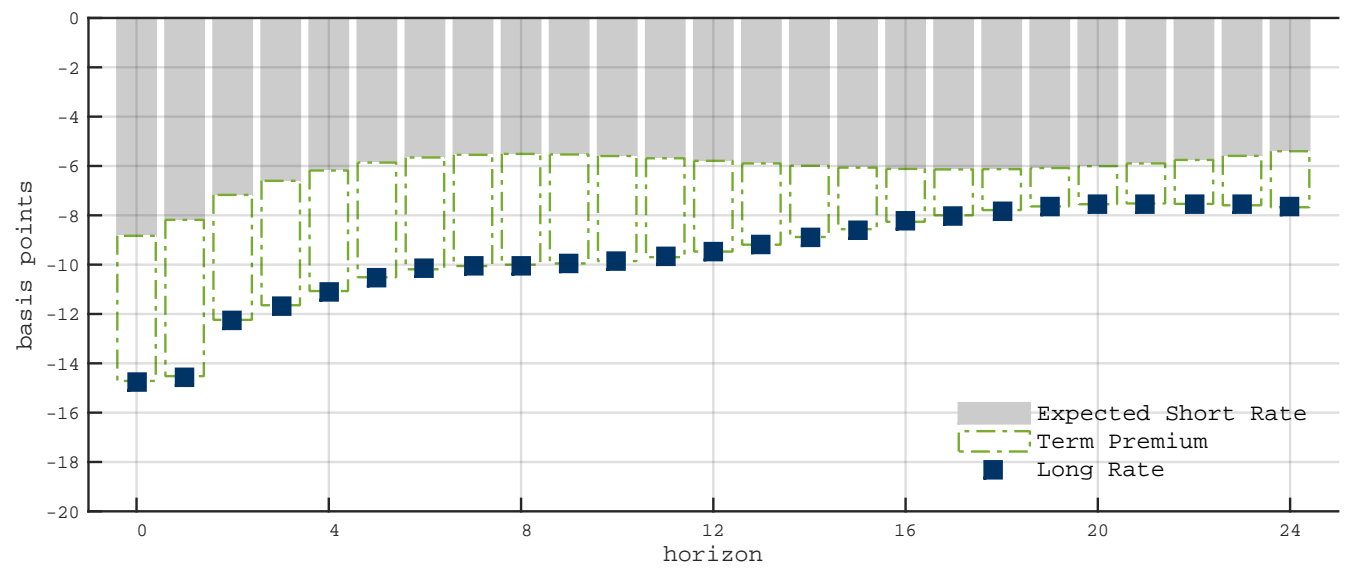

Note: Implied modal responses of the 10-year Treasury yield and VAR-based expectation and term premium components. VAR(4). Estimation sample 1971-I:2016-IV; Identification sample 1981-1:2006IV.

frictions in the setting of prices. If capital is not fixed, lower expected future prices may lead to delayed purchases, and thus to a reduction in labor demand that could offset the wealth effect, and lead to a decline in real wages. This mechanism adds to the left shift in labor supply; hence, ultimately, the effect of a news shock on wages will depend on the relative strength of these two mechanisms, which in turn depends on labor elasticity and the strength of policy accommodation. For example, a low Frisch elasticity parameter combined with a relatively weak policy accommodation to technology shocks would induce a drop in real wages such as that the one we document. Real wage inertia, by acting directly on the upward wage pressure that follows the reduced supply of labor, introduces another channel through which the low inflation environment can be reproduced (Barsky and Sims, 2009; Jinnai, 2013). ${ }^{34}$

Monetary Policy, the Natural Rate of Interest, and the Term Premium Expectations that productivity will be higher in the future, but that do not change the level of current technology, give rise to an inefficient rise in current spending, primarily driven by the desire to increase current consumption. In order to keep spending anchored to the current (unchanged) level of technology, the natural rate of interest, proportional to

\footnotetext{
${ }^{34}$ Den Haan and Kaltenbrunner (2009) and Den Haan and Lozej (2011) discuss alternative channels through which the presence of wage rigidities affects the propagation of news shocks in search and matching models for the labor market.
} 
the expected growth rate of technology, rises sharply. Consider now a central bank that sets the nominal interest rate as a function of expected inflation. This is the situation analyzed in detail in Christiano et al. (2010). Expectations that inflation will be lower in the future lead the central bank to lower the nominal interest rate precisely when the natural rate is increasing, thus creating an amplification mechanism for the propagation of the news shock. ${ }^{35}$ The dynamic responses from our VAR abide by this narrative. As discussed, the one year rate moves by roughly the same amount as the deflator at peak, implying an even larger drop of shorter maturity interest rates. Hence, in our empirical setting the monetary authority responds to the news shock by aggressively reacting to the fall in (expected) inflation. The suboptimal response of the central bank can be rationalized in terms of information rigidities: the monetary authority may have to calibrate its response based on its best forecasts for (current and future) technology, which may diverge from the realized values (see e.g. Lorenzoni, 2011). ${ }^{36}$ Finally, comparing the responses of the short and long term rates, we note that the 1-year rate returns to trend relatively quickly, and is hence likely not to fully account for the impact fall in the 10-year Treasury yield. This implies that following the news shock term premia decline. We confirm this intuition in Figure VIII. Here we plot the responses of the long term rate implied by Figure VII, and use the VAR to decompose it into its expectation and term premium components. ${ }^{37}$ About $3 / 5$ of the impact decline in the long term interest rate is estimated to be due to a fall in term premia; and the response dies out relatively slowly. The fall in term premia is consistent with consumption and inflation moving in opposite directions, thus breaking the correlation between bonds and stocks which also diverge after the shock (see e.g. Piazzesi and Schneider, 2007; Campbell et al., 2009).

\footnotetext{
${ }^{35}$ See also discussion in Sims (2012a). Gambetti et al. (2017) explore the interaction between news shocks and monetary policy regimes and document time-variation in responses computed prior to and after the Fed's reserve targeting period (1979-1982).

${ }^{36}$ As a partial solution to this issue, Christiano et al. (2010) suggest introducing variables that help to proxy for the natural rate, such as e.g. credit growth, in the reaction function.

${ }^{37}$ The 10-year yield can be decomposed into the expected 1-year rate over 10 years, plus a term premium $\zeta_{t}$. If $t$ denotes quarters,

$$
y_{t}^{(10)}=\mathbb{E}_{t}\left[\frac{1}{10} \sum_{\tau=1}^{10} y_{t+4 \times(\tau-1)}^{(1)}\right]+\zeta_{t}^{(10)} .
$$

Net of risk considerations, holding a 10-year bond should be equivalent to rolling 1-year bonds over 10 years. We calculate horizon $h$ term premium responses as the difference between the horizon $h$ response of the 10-year rate, and the average expected response of the 1 -year rate at horizons $h, h+4, \ldots, h+36$.
} 
These findings align with those in Crump et al. (2016).

Financial Amplification Channels The combination of low nominal interest rates and high asset prices in response to a positive news shock may be responsible of a further amplification mechanisms that works through the relaxation of borrowing constraints - particularly collateral constraints - (see e.g. Kobayashi et al., 2012; Walentin, 2014; Görtz et al., 2016; Görtz and Tsoukalas, 2017). On one hand, loser borrowing/leverage constraints can increase the demand for investment goods. On the other, they may affect the ability of the firm to vary the inputs and increase its demand of labor. Finally, they could lead to more efficient capital allocation towards more productive firms. This is another channel through which news may spill over to current TFP (see Jermann and Quadrini, 2007). In our VAR, we find that corporate spreads eventually compress, but the effect is not estimated to be particularly strong. Rather, we find that financial amplification may work through the compression of term premia.

Consumer Expectations We lastly turn to analyze the response of consumer expectations. As discussed, upon realization of the shock both the index of consumer confidence and the component of the Michigan Survey of Consumers that relates to business conditions expected 5 years hence decline sharply. The decline is short-lived, and both indicators robustly rise above trend within a year after the shock hits. While the sharp negative responses are only marginally significant, they are nevertheless somewhat puzzling. We offer an interpretation for this finding that builds on the presence of information rigidities. In fact, a potential explanation for this result is that agents only imperfectly observe future fundamentals, and overweigh current economic conditions when forming their expectations about the future when the signal-to-noise ratio is low.

In a comprehensive study, Coibion and Gorodnichenko $(2012,2015)$ analyze survey forecasts of consumers, firms, professional forecasters and central banks, and find that economic agents face strong information rigidities, irrespective of their type. The empirical regularities unveiled in these studies describe frictions to information processing that seem to be more coherent with frameworks in which agents continuously update their information set, but only receive noisy signals about the state of the economy (noisy 


\section{Figure IX: Role of Unemployment ExpeCtations}
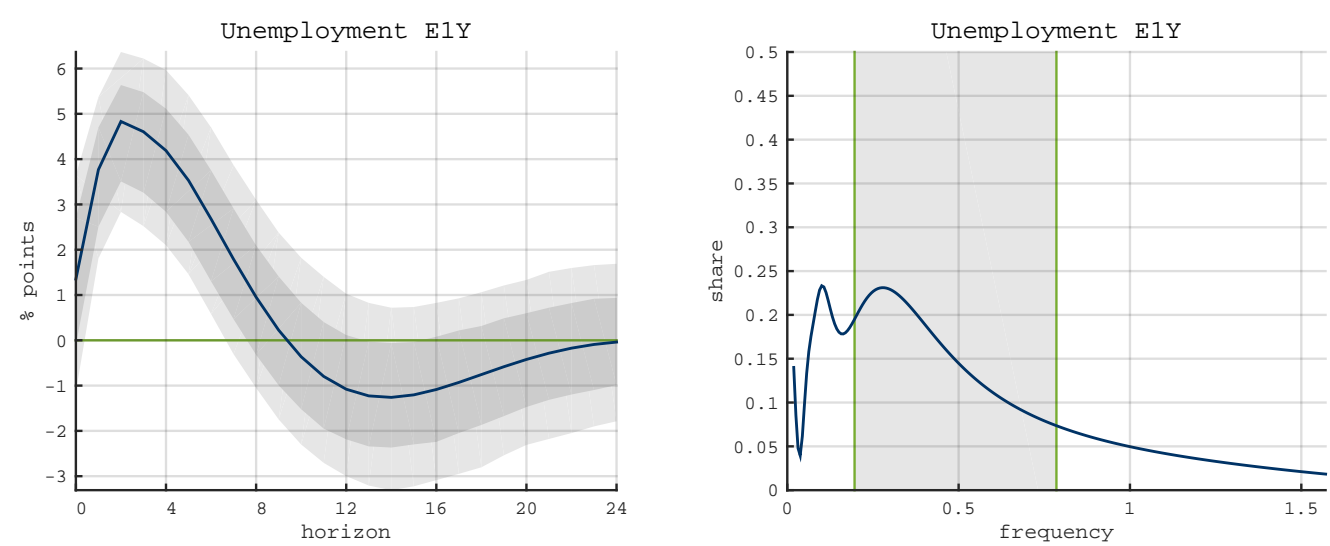

Note: Impulse response (left panel) and share of variance (right panel) of 1-year-ahead unemployment expectation and due to the identified technology news shock. Survey forecasts are from the Michigan Survey of Consumers. VAR(4). Estimation sample 1971-I:2016-IV; Identification sample 1981-1:2006-IV.

information, Woodford, 2003; Sims, 2003; Mackowiak and Wiederholt, 2009), as opposed to alternatives in which the update itself is inertial (sticky information, Mankiw and Reis, 2002). In the noisy information environment, agents never fully observe the true states, and form expectations about fundamentals via a signal extraction problem. Hence, at any given time agents' forecasts are a combination of existing beliefs and new information received, with relative weights determined by the degree of information rigidity (i.e. noise in the signal). Coibion and Gorodnichenko (2015) estimate that new information receives less than half the weight it would otherwise have under full-information. News about future technological changes can be thought of as a quintessential signal extraction problem (see also Chahrour and Jurado, 2018b). Blanchard et al. (2013) consider the case in which technology is driven by both temporary and permanent shocks (i.e. shocks that have long-lasting effects on the level of technology), and agents observe a noisy signal of the permanent component of technology. Agents are not able to disentangle news from noise; moreover, the noisier the signal, the slower the consumption adjustment, the more likely that shocks to the permanent component result in an initial fall in employment.

To offer some additional insights, in Figure IX we report the response of consumers' expectations about year ahead unemployment, again extracted from the Michigan Survey of Consumers. ${ }^{38}$ Following the positive news shock expected unemployment rises,

\footnotetext{
${ }^{38}$ We augment the VAR of Section 4 with the series of unemployment forecasts. All other details of the VAR specification stay the same. Full IRFs are in Figure D.III.
} 
and does so very significantly. The peak is realized well within the first year, and the shock explains a non trivial fraction of variation of unemployment forecasts at business cycle frequencies (see also Faccini and Melosi, 2018, for the role played by technology news on employment and its forecasts). We think of the rise in expected unemployment as compatible with such noise-ridden environment, and with agents overweighting the negative impact response of labor market variables to the shock. In turn, this can help explain the initial fall in consumer confidence about both current and expected economic conditions. ${ }^{39}$ Barsky and Sims $(2009,2012)$ use innovations in consumer confidence to infer on the effect of news shocks, arguing that measures of confidence aggregate information about future income that is otherwise unavailable in current consumption data, an intuition first offered in Cochrane (1994). ${ }^{40}$ The responses in Figure VII suggest that confidence 'innovations' may in fact be anticipated.

Contemporaneous TFP Innovations A last observation on our identification strategy is in order. We have identified shocks to future technology using an external instrument that is constructed as the unforecastable component of utility patent applications that are filed each quarter at the USPTO (see Section 2). Differently from virtually all the existing empirical literature, the use of an external instrument has allowed us to dispense from a priori assumptions related to the duration of the effects, the long-run drivers of technology, or the length of time that is required to the news to affect the current level of technology. Using patents applications as the starting point for the construction of our instrument ensures that it embeds an element of news. However, because new technologies can be potentially distributed under a patent-pending status, our identification strategy does not rule out ex ante that the effect of the news shock on current technology must be zero on impact, which is the standard assumption in the news literature. While we have discussed theoretical grounds that justify the absence of this orthogonality constraint in our identification scheme, and documented the effective zero impact response of TFP estimated in the data, a doubt may still remain that our estimated dynamic responses

\footnotetext{
${ }^{39}$ The fall in the forward looking component of the Michigan Survey of Consumers is a particularly relevant piece of evidence in favor of the slow adjustment of expectations over time.

${ }^{40}$ In Barsky and Sims (2012) positive confidence innovations are associated with little immediate response of real activity, prolonged and sustained increases in consumption and income, a fall in inflation, and a marked increase in the real interest rate.
} 


\section{Figure X: Impact Responses to a Contemporaneous TFP Innovation}

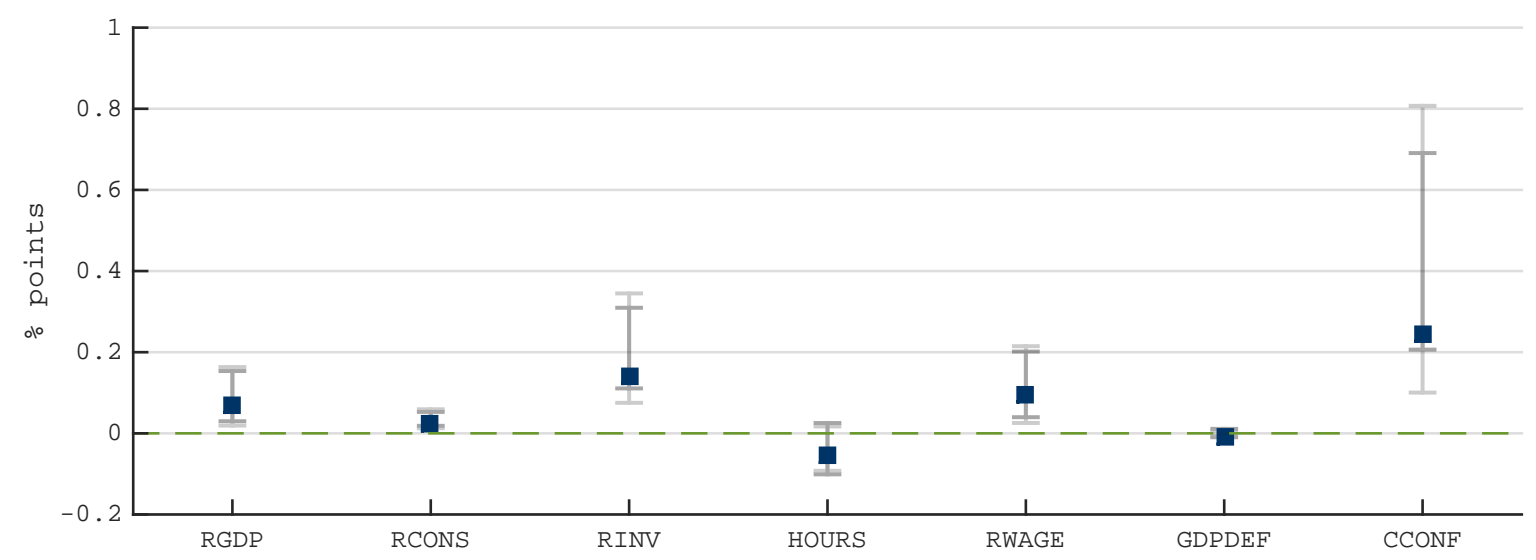

Note: Impact responses of selected variables to a TFP innovation that increases Utilization-Adjusted TFP by 1\%. VAR(4). Estimation sample 1971-I:2016-IV. Grey bars delimit $68 \%$ and $90 \%$ posterior coverage bands.

may be confounding the effects of news shocks with those of an unanticipated innovation in the technology process. To provide some evidence that in fact this does not seem to be a cause of concern, Figure X reports impact responses of a selection of variables to a contemporaneous TFP innovation estimated using the same VAR of Section $4 .{ }^{41}$ These are impact responses at the mode of the posterior distribution of the parameters obtained with a standard Cholesky factorization with TFP ordered first, and scaled such that the impact response of TFP is $1 \% .{ }^{42}$

The pattern of impact responses in Figure $\mathrm{X}$ is fundamentally different from those elicited by the news shock. A positive contemporaneous TFP innovation significantly moves up output, consumption and investment on impact, while the response of hours is muted. Real wages increase robustly, and so do consumer expectations. Finally, there seems to be no appreciable impact reaction of the price level.

\footnotetext{
${ }^{41}$ Full IRFs are not reported for space considerations, but available upon request.

${ }^{42}$ This identification scheme assumes that the technology process is exogenous and only driven by technology shocks, and that the quarterly series of Fernald (2014) measures true technology without systematic error. Both these assumptions have been questioned in the literature (e.g. in Kurmann and Sims, 2017; Bouakez and Kemoe, 2017). This is however inconsequential, since the focus of our paper is rather on the effects of anticipated news to technology, and our identification scheme to news shocks is robust to mismeasurements. Here we rely on standard Cholesky ordering only to highlight the differences between the impact effects of the two types of shocks.
} 


\section{Conclusions}

'How does the aggregate economy react to a shock that raises expectations about future productivity growth?'. In this paper we have provided an answer to this question by introducing a novel identification of technology news shocks in a rich-information VAR. We have constructed an external instrument for identification of technology news shocks by exploiting a largely unexplored dataset of all monthly utility patent applications filed at the USPTO over the past 30 years.

We estimate a pattern of dynamic responses that is consistent with the predictions of New-Keynesian models featuring nominal rigidities, particularly those that arise endogenously because of the presence of noisy-information environments.

Our main conclusions are as follows. i) The identified technology news shock affects total factor productivity only after 4 years, by which time the dynamics of all other variables in our VAR are exhausted. Hence, there is evidence of news about future fundamentals triggering business cycle type fluctuations. ii) The shock explains about a 10th of fluctuations in aggregate economic variables at business cycle frequencies, and only $40 \%$ of the variation of TFP at very low frequencies. On the one hand, these results suggest that news, while being relevant, are not the main drivers of business cycle dynamics. On the other hand, they render previously adopted 'max-share' type identifications potentially problematic. iii) The shock is disinflationary. While this conclusion is not per se surprising, we find that prices only slowly contract over time. Conversely, nominal wages take the worse hit, and strongly contract on impact to increase at longer horizons. iv) The monetary authority responds to the positive technology news shock by lowering nominal interest rates, at a time when the natural rate of interest, proportional to the expected growth rate of future technology, is increasing. This suboptimal reaction of the central bank helps fostering the ensuing economic expansion, also through the effect of compressed term premia. v) While the stock market prices-in the technology news shock on impact, consumers expectations take sensibly longer to adjust. In particular, consumers seem to overweigh the initial contraction in both hours worked and real wages when forming expectations about future unemployment. In turn, this leads to an initial downward revision of expected economic conditions five years hence. 
The reactions of consumers, market participants and the central bank to the identified technology news shock seem to point towards a substantial degree of heterogeneity in their expectation formation process. All concur to highlight the role that dispersed information about changes in future fundamentals may have influence in shaping the response of different types of agents to such types of disturbances. We leave further investigation of these relevant issues to future research. 


\section{References}

Alexopoulos, Michelle (2011) "Read All about It!! What Happens Following a Technology Shock?," American Economic Review, Vol. 101, No. 4, pp. 1144-1179, June.

Altig, David, Lawrence Christiano, Martin Eichenbaum, and Jesper Linde (2005) "Online Appendix to "Firm-Specific Capital, Nominal Rigidities and the Business Cycle"," Technical Appendices 09-191, Review of Economic Dynamics.

(2011) "Firm-Specific Capital, Nominal Rigidities and the Business Cycle," Review of Economic Dynamics, Vol. 14, No. 2, pp. 225-247, April.

Angeletos, George-Marios and Jennifer La'O (2010) "Noisy Business Cycles," NBER Macroeconomics Annual, Vol. 24, No. 1, pp. 319-378.

Arezki, Rabah, Valerie A. Ramey, and Liugang Sheng (2017) "News Shocks in Open Economies: Evidence from Giant Oil Discoveries*," The Quarterly Journal of Economics, Vol. 132, No. 1, pp. 103-155.

Baron, J. and J. Schmidt (2014) "Technological Standardization, Endogenous Productivity and Transitory Dynamics," Working Papers 503, Banque de France.

Barro, Robert and Robert G. King (1984) "Time-Separable Preferences and IntertemporalSubstitution Models of Business Cycles," The Quarterly Journal of Economics, Vol. 99, No. 4, pp. 817-839.

Barsky, Robert B. and Eric R. Sims (2009) "News Shocks," Working Paper 15312, National Bureau of Economic Research.

(2011) "News shocks and business cycles," Journal of Monetary Economics, Vol. 58, No. 3, pp. 273-289.

(2012) "Information, Animal Spirits, and the Meaning of Innovations in Consumer Confidence," American Economic Review, Vol. 102, No. 4, pp. 1343-77, June.

Barsky, Robert B., Susanto Basu, and Keyoung Lee (2015) "Whither News Shocks?," NBER Macroeconomics Annual, Vol. 29, No. 1, pp. 225-264.

Basu, Susanto, John G. Fernald, and Miles S. Kimball (2006) "Are Technology Improvements Contractionary?" American Economic Review, Vol. 96, No. 5, pp. 1418-1448, December.

Beaudry, Paul and Bernd Lucke (2010) "Letting Different Views about Business Cycles Compete," NBER Macroeconomics Annual, Vol. 24, No. 1, pp. 413-456.

Beaudry, Paul and Franck Portier (2004) "An exploration into Pigou's theory of cycles," Journal of Monetary Economics, Vol. 51, No. 6, pp. 1183-1216, September.

(2006) "Stock Prices, News, and Economic Fluctuations," American Economic Review, Vol. 96, No. 4, pp. 1293-1307, September.

(2014) "News-Driven Business Cycles: Insights and Challenges," Journal of Economic Literature, Vol. 52, No. 4, pp. 993-1074, December. 
Beaudry, Paul, Patrick Fève, Alain Guay, and Franck Portier (2015) "When is Nonfundamentalness in VARs a Real Problem? An Application to News Shocks," NBER Working Papers 21466, National Bureau of Economic Research, Inc.

(2016) "When is Nonfundamentalness in SVARs A Real Problem?," TSE Working Papers 16-738, Toulouse School of Economics (TSE).

Ben Zeev, Nadav (2018) "What can we learn about news shocks from the late 1990s and early 2000s boom-bust period?," Journal of Economic Dynamics and Control, Vol. 87, No. C, pp. 94-105.

Ben Zeev, Nadav and Hashmat Khan (2015) "Investment-Specific News Shocks and U.S. Business Cycles," Journal of Money, Credit and Banking, Vol. 47, No. 7, pp. 1443-1464.

Blanchard, Olivier J., Jean-Paul L'Huillier, and Guido Lorenzoni (2013) "News, Noise, and Fluctuations: An Empirical Exploration," American Economic Review, Vol. 103, No. 7, pp. 3045-3070, December.

Bouakez, Hafedh and Laurent Kemoe (2017) "News Shocks, Business Cycles, and the Disinflation Puzzle," Cahiers de recherche 5, Centre interuniversitaire de recherche en économie quantitative, CIREQ.

Calvo, Guillermo A. (1983) "Staggered prices in a utility-maximizing framework," Journal of Monetary Economics, Vol. 12, No. 3, pp. 383 - 398.

Campbell, John Y., Adi Sunderam, and Luis M. Viceira (2009) "Inflation Bets or Deflation Hedges? The Changing Risks of Nominal Bonds," NBER Working Papers 14701, National Bureau of Economic Research, Inc.

Canova, Fabio, David Lopez-Salido, and Claudio Michelacci (2009) "The effects of technology shocks on hours and output: a robustness analysis," Journal of Applied Econometrics, Vol. 25 , No. 5 , pp. $755-773$.

Carley, Michael, Deepak Hedge, and Alan C. Marco (2015) "What is the Probability of Receiving a U.S. Patent?" Yale Journal of Law and Technology, Vol. 17, No. 1, pp. 201-223.

Cascaldi-Garcia, Danilo (2017) "News Shocks and the Slope of the Term Structure of Interest Rates: Comment," American Economic Review, Vol. 107, No. 10, pp. 3243-49, October.

Chahrour, Ryan and Kyle Jurado (2018a) "Recoverability." Duke University, mimeo. (2018b) "News or Noise? The Missing Link," American Economic Review, Vol. 108, No. 7 , pp. 1702-36, July.

Christiano, Lawrence J., Martin Eichenbaum, and Robert Vigfusson (2003) "What Happens After a Technology Shock?," NBER Working Papers 9819, National Bureau of Economic Research, Inc.

Christiano, Lawrence J., Cosmin Ilut, Roberto Motto, and Massimo Rostagno (2010) "Monetary policy and stock market booms," Proceedings - Economic Policy Symposium - Jackson Hole, pp. $85-145$.

Christiansen, Lone Engbo (2008) "Do Technology Shocks Lead to Productivity Slowdowns? Evidence from Patent Data," IMF Working Papers 08/24, International Monetary Fund. 
Cochrane, John H. (1994) "Shocks," Carnegie-Rochester Conference Series on Public Policy, Vol. 41, No. 1, pp. 295-364, December.

Coibion, Olivier and Yuriy Gorodnichenko (2012) "What Can Survey Forecasts Tell Us about Information Rigidities?" Journal of Political Economy, Vol. 120, No. 1, pp. 116 - 159.

(2015) "Information Rigidity and the Expectations Formation Process: A Simple Framework and New Facts," American Economic Review, Vol. 105, No. 8, pp. 2644-78.

Comin, Diego and Mark Gertler (2006) "Medium-Term Business Cycles," American Economic Review, Vol. 96, No. 3, pp. 523-551, June.

Comin, Diego and Bart Hobijn (2010) "An Exploration of Technology Diffusion," American Economic Review, Vol. 100, No. 5, pp. 2031-2059, December.

Comin, Diego A., Mark Gertler, and Ana Maria Santacreu (2009) "Technology Innovation and Diffusion as Sources of Output and Asset Price Fluctuations," NBER Working Papers 15029, National Bureau of Economic Research, Inc.

Crump, Richard K., Stefano Eusepi, and Emanuel Moench (2016) "The term structure of expectations and bond yields," Staff Reports, revised 2018 775, Federal Reserve Bank of New York.

David, Paul A. (1990) "The Dynamo and the Computer: An Historical Perspective on the Modern Productivity Paradox," The American Economic Review, Vol. 80, No. 2, pp. 355361.

Den Haan, Wouter J. and Georg Kaltenbrunner (2009) "Anticipated growth and business cycles in matching models," Journal of Monetary Economics, Vol. 56, No. 3, pp. 309-327, April.

Den Haan, Wouter J. and Matija Lozej (2011) "Pigou Cycles in Closed and Open Economies with Matching Frictions," NBER International Seminar on Macroeconomics, Vol. 7, No. 1, pp. 193-234.

Doan, Thomas, Robert B. Litterman, and Christopher A. Sims (1983) "Forecasting and Conditional Projection Using Realistic Prior Distributions," NBER Working Papers 1202, National Bureau of Economic Research, Inc.

Erceg, Christopher J., Dale W. Henderson, and Andrew T. Levin (2000) "Optimal monetary policy with staggered wage and price contracts," Journal of Monetary Economics, Vol. 46, No. 2, pp. 281-313, October.

Faccini, Renato and Leonardo Melosi (2018) "News and Noise in the Post-Great Recession Recovery," June. mimeo.

Fernald, John G. (2007) "Trend breaks, long-run restrictions, and contractionary technology improvements," Journal of Monetary Economics, Vol. 54, No. 8, pp. 2467-2485, November.

(2014) "A quarterly, utilization-adjusted series on total factor productivity," Working Paper Series 2012-19, Federal Reserve Bank of San Francisco.

Fernández-Villaverde, Jesús, Juan F. Rubio-Ramírez, Thomas J. Sargent, and Mark W. Watson (2007) "ABCs (and Ds) of Understanding VARs," American Economic Review, Vol. 97, No. 3, pp. 1021-1026, June. 
Fève, Patrick, Julien Matheron, and Jean-Guillaume Sahuc (2009) "On the dynamic implications of news shocks," Economics Letters, Vol. 102, No. 2, pp. 96 - 98.

Fisher, Jonas D. M. (2006) "The Dynamic Effects of Neutral and Investment-Specific Technology Shocks," Journal of Political Economy, Vol. 114, No. 3, pp. 413-451, June.

Forni, Mario and Luca Gambetti (2011) "Testing for Sufficient Information in Structural VARs," CEPR Discussion Papers 8209, C.E.P.R. Discussion Papers.

Forni, Mario, Luca Gambetti, and Luca Sala (2014) "No News in Business Cycles," Economic Journal, Vol. 124, No. 581, pp. 1168-1191, December.

(2018) "Reassessing Structural VARs: Beyond the ABCs (and Ds)." mimeo.

Francis, Neville and Valerie A. Ramey (2005) "Is the technology-driven real business cycle hypothesis dead? Shocks and aggregate fluctuations revisited," Journal of Monetary Economics, Vol. 52, No. 8, pp. 1379-1399, November.

(2009) "Measures of per Capita Hours and Their Implications for the Technology-Hours Debate," Journal of Money, Credit and Banking, Vol. 41, No. 6, pp. 1071-1097, September.

Francis, Neville, Michael T. Owyang, Jennifer E. Roush, and Riccardo DiCecio (2014) "A Flexible Finite-Horizon Alternative to Long-Run Restrictions with an Application to Technology Shocks," The Review of Economics and Statistics, Vol. 96, No. 4, pp. 638-647.

Fujiwara, Ippei, Yasuo Hirose, and Mototsugu Shintani (2011) "Can News Be a Major Source of Aggregate Fluctuations? A Bayesian DSGE Approach," Journal of Money, Credit and Banking, Vol. 43, No. 1, pp. 1-29.

Galí, Jordi (1999) "Technology, Employment, and the Business Cycle: Do Technology Shocks Explain Aggregate Fluctuations?" American Economic Review, Vol. 89, No. 1, pp. 249-271, March.

Gambetti, Luca, Dimitris Korobilis, John D. Tsoukalas, and Francesco Zanetti (2017) "The Effect of News Shocks and Monetary Policy," Discussion Papers 1730, Centre for Macroeconomics (CFM).

Giannone, Domenico and Lucrezia Reichlin (2006) "Does information help recovering structural shocks from past observations?," Journal of the European Economic Association, Vol. 4, No. 2-3, pp. 455-465, 04-05.

Giannone, Domenico, Michele Lenza, and Giorgio E. Primiceri (2015) "Prior Selection for Vector Autoregressions," Review of Economics and Statistics, Vol. 97, No. 2, pp. 436-451.

Gort, Michael and Steven Klepper (1982) "Time Paths in the Diffusion of Product Innovations," The Economic Journal, Vol. 92, No. 367, pp. 630-653.

Görtz, Christoph and John D. Tsoukalas (2017) "News and Financial Intermediation in Aggregate Fluctuations," The Review of Economics and Statistics, Vol. 99, No. 3, pp. 514-530, July.

Görtz, Christoph, John D. Tsoukalas, and Francesco Zanetti (2016) "News Shocks under Financial Frictions," Working Papers 2016, Business School - Economics, University of Glasgow. 
Griliches, Zvi (1957) "Hybrid Corn: An Exploration in the Economics of Technological Change," Econometrica, Vol. 25, No. 4, pp. 501-522.

(1990) "Patent Statistics as Economic Indicators: A Survey," Journal of Economic Literature, Vol. 28, No. 4, pp. 1661-1707.

Hall, Bronwyn H. (2006) "Innovation and Diffusion," in Jan Fagerberg and David C. Mowery eds. The Oxford Handbook of Innovation: Oxford University Press.

Hall, Bronwyn H. and Manuel Trajtenberg (2004) "Uncovering GPTS with Patent Data," Working Paper 10901, National Bureau of Economic Research.

Hall, Bronwyn H., Adam B. Jaffe, and Manuel Trajtenberg (2001) "The NBER Patent Citation Data File: Lessons, Insights and Methodological Tools," Working Paper 8498, National Bureau of Economic Research.

Hansen, Lars P. and Thomas J. Sargent (1980) "Formulating and estimating dynamic linear rational expectations models," Journal of Economic Dynamics and Control, Vol. 2, No. 1, pp. 7-46, May.

(1991) "Two problems in interpreting vector autoregressions," in Rational Expectations Econometrics: Boulder, pp. 77-119.

Jaimovich, Nir and Sergio Rebelo (2009) "Can News about the Future Drive the Business Cycle?," American Economic Review, Vol. 99, No. 4, pp. 1097-1118, September.

Jermann, Urban J. and Vincenzo Quadrini (2007) "Stock market boom and the productivity gains of the 1990s," Journal of Monetary Economics, Vol. 54, No. 2, pp. 413 - 432.

Jinnai, Ryo (2013) "News shocks and inflation," Economics Letters, Vol. 119, No. 2, pp. 176 179.

Justiniano, Alejandro, Giorgio E. Primiceri, and Andrea Tambalotti (2010) "Investment shocks and business cycles," Journal of Monetary Economics, Vol. 57, No. 2, pp. 132-145, March.

Justiniano, Alejandro, Giorgio Primiceri, and Andrea Tambalotti (2011) "Investment Shocks and the Relative Price of Investment," Review of Economic Dynamics, Vol. 14, No. 1, pp. 101-121, January.

Kadiyala, K Rao and Sune Karlsson (1997) "Numerical Methods for Estimation and Inference in Bayesian VAR-Models," Journal of Applied Econometrics, Vol. 12, No. 2, pp. 99-132, March-Apr.

Khan, Hashmat and John Tsoukalas (2012) "The Quantitative Importance of News Shocks in Estimated DSGE Models," Journal of Money, Credit and Banking, Vol. 44, No. 8, pp. 1535-1561, December.

Kobayashi, Keiichiro, Tomoyuki Nakajima, and Masaru Inaba (2012) "Collateral Constraint And News-Driven Cycles," Macroeconomic Dynamics, Vol. 16, No. 05, pp. 752-776, November.

Kurmann, André and Elmar Mertens (2014) "Stock Prices, News, and Economic Fluctuations: Comment," American Economic Review, Vol. 104, No. 4, pp. 1439-1445, April. 
Kurmann, André and Christopher Otrok (2013) "News Shocks and the Slope of the Term Structure of Interest Rates," American Economic Review, Vol. 103, No. 6, pp. 2612-2632, October.

_ (2014) "News Shocks and Inflation: Lessons for New Keynesians." Unpublished. - (2017) "News Shocks and the Slope of the Term Structure of Interest Rates: Reply," American Economic Review, Vol. 107, No. 10, pp. 3250-56, October.

Kurmann, André and Eric R. Sims (2017) "Revisions in Utilization-Adjusted TFP and Robust Identification of News Shocks," Working Paper 23142, National Bureau of Economic Research.

Lach, Saul (1995) "Patents and productivity growth at the industry level: A first look," Economics Letters, Vol. 49, No. 1, pp. $101-108$.

Leeper, Eric M., Todd B. Walker, and Shu-Chun Susan Yang (2013) "Fiscal Foresight and Information Flows," Econometrica, Vol. 81, No. 3, pp. 1115-1145.

Lindé, Jesper (2009) "The effects of permanent technology shocks on hours: Can the RBCmodel fit the VAR evidence?" Journal of Economic Dynamics and Control, Vol. 33, No. 3, pp. $597-613$.

Lippi, Marco and Lucrezia Reichlin (1993) "The Dynamic Effects of Aggregate Demand and Supply Disturbances: Comment," American Economic Review, Vol. 83, No. 3, pp. 644-652, June.

(1994) "VAR analysis, nonfundamental representations, Blaschke matrices," Journal of Econometrics, Vol. 63, No. 1, pp. 307-325, July.

Litterman, Robert B (1986) "Forecasting with Bayesian Vector Autoregressions-Five Years of Experience," Journal of Business \& Economic Statistics, Vol. 4, No. 1, pp. 25-38, January.

Lorenzoni, Guido (2009) "A Theory of Demand Shocks," American Economic Review, Vol. 99, No. 5, pp. 2050-84, December.

(2011) "News and Aggregate Demand Shocks," Annual Review of Economics, Vol. 3, No. 1, pp. 537-557, September.

Mackowiak, Bartosz and Mirko Wiederholt (2009) "Optimal Sticky Prices under Rational Inattention," American Economic Review, Vol. 99, No. 3, pp. 769-803, June.

Mankiw, N. Gregory and Ricardo Reis (2002) "Sticky Information Versus Sticky Prices: A Proposal To Replace The New Keynesian Phillips Curve," The Quarterly Journal of Economics, Vol. 117, No. 4, pp. 1295-1328, November.

Mansfield, Edwin (1961) "Technical Change and the Rate of Imitation," Econometrica, Vol. 29, No. 4, pp. 741-766.

Marco, Alan C., Michael Carley, Steven Jackson, and Amanda Myers (2015) "The USPTO Historical Patent Data Files: Two Centuries of Innovation," USPTO Economic Working Papers 1, U.S. Patent and Trademark Office. 
McCracken, Michael W. and Serena Ng (2015) "FRED-MD: A Monthly Database for Macroeconomic Research," Working Papers 2015-12, Federal Reserve Bank of St. Louis.

Mertens, Karel and Morten O. Ravn (2011) "Technology-Hours Redux: Tax Changes and the Measurement of Technology Shocks," NBER International Seminar on Macroeconomics, Vol. 7, No. 1, pp. 41-76.

(2012) "Empirical Evidence on the Aggregate Effects of Anticipated and Unanticipated US Tax Policy Shocks," American Economic Journal: Economic Policy, Vol. 4, No. 2, pp. 145-181, May.

(2013) "The Dynamic Effects of Personal and Corporate Income Tax Changes in the United States," American Economic Review, Vol. 103, No. 4, pp. 1212-47, June.

Miranda-Agrippino, Silvia and Hélène Rey (2015) "World Asset Markets and the Global Financial Cycle," NBER Working Papers 21722, National Bureau of Economic Research, Inc.

Miranda-Agrippino, Silvia and Giovanni Ricco (2018) "Identification with External Instruments in Structural VARs under Partial Invertibility," April. mimeo.

Piazzesi, Monika and Martin Schneider (2007) "Equilibrium Yield Curves," in NBER Macroeconomics Annual 2006, Volume 21: National Bureau of Economic Research, Inc, pp. 389-472.

Pigou, A.C. (1927) Industrial Fluctuations: Macmillan and Company, limited.

Ramey, Valerie A. (2016) "Macroeconomic Shocks and Their Propagation," in John B. Taylor and Harald Uhlig eds. Handbook of Macroeconomics, Vol. 2 of Handbook of Macroeconomics: Elsevier, Chap. 2, pp. $71-162$.

Rogers, Everett M. (1962) Diffusion of innovations: The Free Press of Glencoe Division of The Macmillan Co., New York, 1st edition.

Romer, Christina D. and David H. Romer (2004) "A New Measure of Monetary Shocks: Derivation and Implications," American Economic Review, Vol. 94, No. 4, pp. 1055-1084.

(2010) "The Macroeconomic Effects of Tax Changes: Estimates Based on a New Measure of Fiscal Shocks," American Economic Review, Vol. 100, No. 3, pp. 763-801, June.

Rotemberg, Julio J. (2003) "Stochastic Technical Progress, Smooth Trends, and Nearly Distinct Business Cycles," American Economic Review, Vol. 93, No. 5, pp. 1543-1559, December.

Schmitt-Grohé, Stephanie and Martín Uribe (2012) "What's News in Business Cycles," Econometrica, Vol. 80, No. 6, pp. 2733-2764, November.

Shea, John (1999) "What Do Technology Shocks Do?," in NBER Macroeconomics Annual 1998, volume 13: National Bureau of Economic Research, Inc, pp. 275-322.

Sims, Christopher A. (2003) "Implications of rational inattention," Journal of Monetary Economics, Vol. 50, No. 3, pp. 665 - 690. Swiss National Bank/Study Center Gerzensee Conference on Monetary Policy under Incomplete Information.

Sims, Eric R. (2012a) "Taylor rules and technology shocks," Economics Letters, Vol. 116, No. 1, pp. 92-95. 
(2012b) "News, Non-Invertibility, and Structural VARs," Working Papers 013, University of Notre Dame, Department of Economics.

(2016) "Whats news in News? A cautionary note on using a variance decomposition to assess the quantitative importance of news shocks," Journal of Economic Dynamics and Control, Vol. 73, No. C, pp. 41-60.

Stock, James H. and Mark W. Watson (2012) "Disentangling the Channels of the 2007-09 Recession," Brookings Papers on Economic Activity, Vol. 44, No. 1 (Spring, pp. 81-156.

(2018) "Identification and Estimation of Dynamic Causal Effects in Macroeconomics Using External Instruments," The Economic Journal, Vol. 128, No. 610, pp. 917-948.

Uhlig, Harald (2004) "Do Technology Shocks Lead to a Fall in Total Hours Worked?," Journal of the European Economic Association, Vol. 2, No. 2-3, pp. 361-371, 04/05.

Walentin, Karl (2014) "Expectation driven business cycles with limited enforcement," Economics Letters, Vol. 124, No. 2, pp. 300 - 303.

Woodford, Michael (2003) "Imperfect Common Knowledge and the Effects of Monetary Policy," in P. Aghion, R. Frydman, J. Stiglitz, and M. Woodford eds. Knowledge, Information, and Expectations in Modern Macroeconomics: In Honor of Edmund Phelps: Princeton University Press. 


\section{A Data Appendix}

Table A.I lists the variables included in the VAR. The construction of real consumption (RCONS), real investment (RINV), the relative price of investment (RPINV), and hours worked (HOURS) follows Justiniano et al. (2010, 2011); specifically,

$$
\begin{aligned}
& R C O N=100 \times \ln \left(\frac{P C N D+P C E S V}{C N P 16 O V \times G D P D E F}\right) \\
& R I N V=100 \times \ln \left(\frac{G P D I+P C D G}{C N P 16 O V \times G D P D E F}\right) \\
& R P I N V=100 \times \ln \left(\frac{D D U R R D 3 Q 086 S B E A+A 006 R D 3 Q 086 S B E A}{D N D G R D 3 Q 086 S B E A+D S E R R D 3 Q 086 S B E A}\right) \\
& H O U R S=100 \times \ln \left(\frac{H O A N B S}{2080}\right),
\end{aligned}
$$

where 2080 is the average numbers of hours worked in a year (i.e. 40 hours a week times 52 weeks). Consumption includes personal consumption expenditures in non-durable goods (PCND) and services (PCESV), whereas investment is constructed as the sum of private gross domestic investment (GPDI) and personal consumption expenditures in durable goods (PCDG). The relative price of investment goods is constructed as the ratio of the deflators of investment and consumption. Consistent with the definition above, these are constructed as the implicit price deflator for durable and investment, and the implicit price deflators for non-durable and services consumption respectively.

The level of Utilization-Adjusted TFP is obtained by cumulating the series in Fernald (2014). The short term rate and the yield curve slope, are expressed in annualized terms. The yield curve slope (YCSLOPE) is constructed as the difference between the 10-year (DGS10) and 1-year (DGS1) Treasury constant-maturity rates. Variables are deflated using the GDP deflator, and transformed in per-capita terms by dividing for the trend in population (population variable: CNP16OV). 
TABle A.I: VARIABles Used

\begin{tabular}{|c|c|c|c|c|c|}
\hline \multirow[b]{2}{*}{ Label } & \multirow[b]{2}{*}{ Variable Name } & \multirow[b]{2}{*}{ Source } & \multirow[b]{2}{*}{ FRED Codes } & \multicolumn{2}{|c|}{ TREATMENT } \\
\hline & & & & $\log$ & $\mathrm{pc}$ \\
\hline TFPL & Utilization-Adj TFP & Fernald $(2014)^{\dagger}$ & - & $\bullet$ & $\bullet$ \\
\hline RGDP & Real GDP & FRED & GDPC1 & $\bullet$ & $\bullet$ \\
\hline RCONS & Real Consumption & FRED & PCND; PCESV & $\bullet$ & $\bullet$ \\
\hline RINV & Real Investment & FRED & GPDI; PCDG & $\bullet$ & $\bullet$ \\
\hline RDGDP & R\&D Expenditures (Y) & FRED & Y694RC1Q027SBEA & $\bullet$ & $\bullet$ \\
\hline HOURS & Hours & FRED & HOANBS & $\bullet$ & $\bullet$ \\
\hline CAPUTIL & Capacity Utilization & FRED & TCU & $\bullet$ & \\
\hline GDPDEF & GDP Deflator & FRED & GDPDEF & $\bullet$ & \\
\hline RPINV & Price of Investment & FRED & $\begin{array}{l}\text { DDURRD3Q086SBEA; } \\
\text { DNDGRD3Q086SBEA; } \\
\text { DSERRD3Q086SBEA; } \\
\text { A006RD3Q086SBEA }\end{array}$ & $\bullet$ & \\
\hline RWAGE & Real Wages & FRED & COMPRNFB & $\bullet$ & \\
\hline SHORTR & Short Rate & FRED & DGS1 & & \\
\hline YCSLOPE & Term Spread & FRED & DGS1; DGS10 & & \\
\hline EQY & Equity Index & FRED $^{*}$ & SP500 & $\bullet$ & \\
\hline EQY2 & Nasdaq & FRED & NASDAQCOM & $\bullet$ & \\
\hline $\mathrm{CCONF}$ & Consumer Confidence & UMICH & - & $\bullet$ & \\
\hline BCE5Y & Business Conditions E5Y & $\mathrm{UMICH}$ & - & $\bullet$ & \\
\hline CBSPREAD & Corporate Bond Spread & FRED & $\mathrm{AAA} ; \mathrm{BAA}$ & & \\
\hline
\end{tabular}

Notes: Sources are: St Louis FRED Database (FRED); University of Michigan (UMICH) Survey of Consumers https://data.sca.isr.umich.edu/charts.php; $\dagger$ Latest vintage of Fernald (2014) TFP series https://www.frbsf.org/economic-research/indicators-data/ total-factor-productivity-tfp/; ${ }^{*}$ Older data are retrieved from WRDS. pc $=$ per-capita. 


\section{B Error Variance Decomposition}

The content of this appendix extends on Altig et al. (2005). Recall Eq. (7), reported below for convenience

$$
B(L) y_{t}=B_{0} e_{t}, \quad e_{t} \sim \mathcal{W N}\left(0, \mathbb{I}_{n}\right)
$$

$B(L) \equiv \mathbb{I}_{n}-\sum_{j=1}^{p} B_{j} L^{j}, e_{t}$ are the structural shocks, and $B_{0}$ contains the contemporaneous transmission coefficients. Recall also that under invertibility

$$
\Sigma=\mathbb{E}\left[u_{t} u_{t}^{\prime}\right]=B_{0} Q\left[e_{t} e_{t}^{\prime}\right] Q^{\prime} B_{0}^{\prime}
$$

for any orthogonal matrix Q. $u_{t}$ are the reduced-form VAR innovations. The external instrument of Section 3 allows identification of only one column $b_{0}$ of $B_{0}$, which contains the impact effects of the identified technology news shock $e_{\mathrm{A}, t}$ on $y_{t}$.

The spectral density of $y_{t}$ is

$$
S_{y}\left(e^{-i \omega}\right)=\left[B\left(e^{-i \omega}\right)\right]^{-1} \Sigma\left[B\left(e^{-i \omega}\right)^{\top}\right]^{-1},
$$

where $i \equiv \sqrt{-1}$, we use $\omega$ to denote the frequency, and $B\left(e^{-i \omega}\right)^{\top}$ is the conjugate transpose of $B\left(e^{-i \omega}\right)$. Let $S_{y}^{A}\left(e^{-i \omega}\right)$ denote the spectral density of $y_{t}$ when only the technology news shock $e_{\mathrm{A}, t}$ is activated. This is equal to

$$
S_{y}^{\mathrm{A}}\left(e^{-i \omega}\right)=\left[B\left(e^{-i \omega}\right)\right]^{-1} \mathrm{~b}_{0} \sigma_{\mathrm{A}} \mathrm{b}_{0}^{\prime}\left[B\left(e^{-i \omega}\right)^{\top}\right]^{-1}
$$

$\sigma_{\mathrm{A}}$ is the variance of $e_{\mathrm{A}, t}$ for which an estimator is given by $\sigma_{\mathrm{A}}=\left(\mathrm{b}_{0}^{\prime} \Sigma^{-1} \mathrm{~b}_{0}\right)^{-1}$ (see Stock and Watson, 2018). Hence, the share of variance due to $e_{\mathrm{A}, t}$ at frequency $\omega$ can be calculated as

$$
\gamma_{\mathrm{A}}(\omega)=\frac{\operatorname{diag}\left(S_{y}^{\mathrm{A}}\left(e^{-i \omega}\right)\right)}{\operatorname{diag}\left(S_{y}\left(e^{-i \omega}\right)\right)},
$$

where the ratio between the two vectors is calculated as the element-by-element division.

The share of variance due to $e_{\mathrm{A}, t}$ over a range of frequencies is calculated using the 
following formula for the variance

$$
\frac{1}{2 \pi} \int_{-\pi}^{\pi} S_{y}\left(e^{-i \omega}\right) d \omega=\lim _{N \rightarrow \infty} \frac{1}{N} \sum_{k=-N / 2+1}^{N / 2} S_{y}\left(e^{-i \omega_{k}}\right),
$$

where $\omega_{k}=2 \pi k / N, k=-N / 2, \ldots, N / 2$.

Recall that the spectrum is symmetric around zero. Let the object of interest be the share of variance explained by $e_{\mathrm{A}, t}$ at business cycle frequencies. These are typically between 2 and 8 years which, with quarterly data, correspond to a period between 8 and 32 quarters. Recall the mapping between frequency and period $\omega=2 \pi / t$. Business cycle frequencies are then in the range $[2 \pi \underline{k} / N 2 \pi \bar{k} / N]$, where $\underline{k}=N / 32$ and $\bar{k}=N / 8$. It follows that the share of fluctuations in $y_{t}$ that is accounted for by $e_{\mathrm{A}, t}$ at business cycle frequencies is equal to

$$
\frac{\sum_{k=\underline{k}}^{\bar{k}} \operatorname{diag}\left(S_{y}^{\mathrm{A}}\left(e^{-i \omega}\right)\right)}{\sum_{k=\underline{k}}^{\bar{k}} \operatorname{diag}\left(S_{y}\left(e^{-i \omega}\right)\right)} .
$$

Figure B.I plots the share of variance that is due to $e_{\mathrm{A}, t}$ for all the variables included in our benchmark VAR at all frequencies between 1 (highest frequency) and 100 (lowest frequency) years. Grey areas highlight business cycle frequencies. Table IV in Section 4 reports the share of variance due to $e_{\mathrm{A}, t}$ over three different ranges of frequencies. 


\section{Figure B.I: ERror VARiance Decomposition}
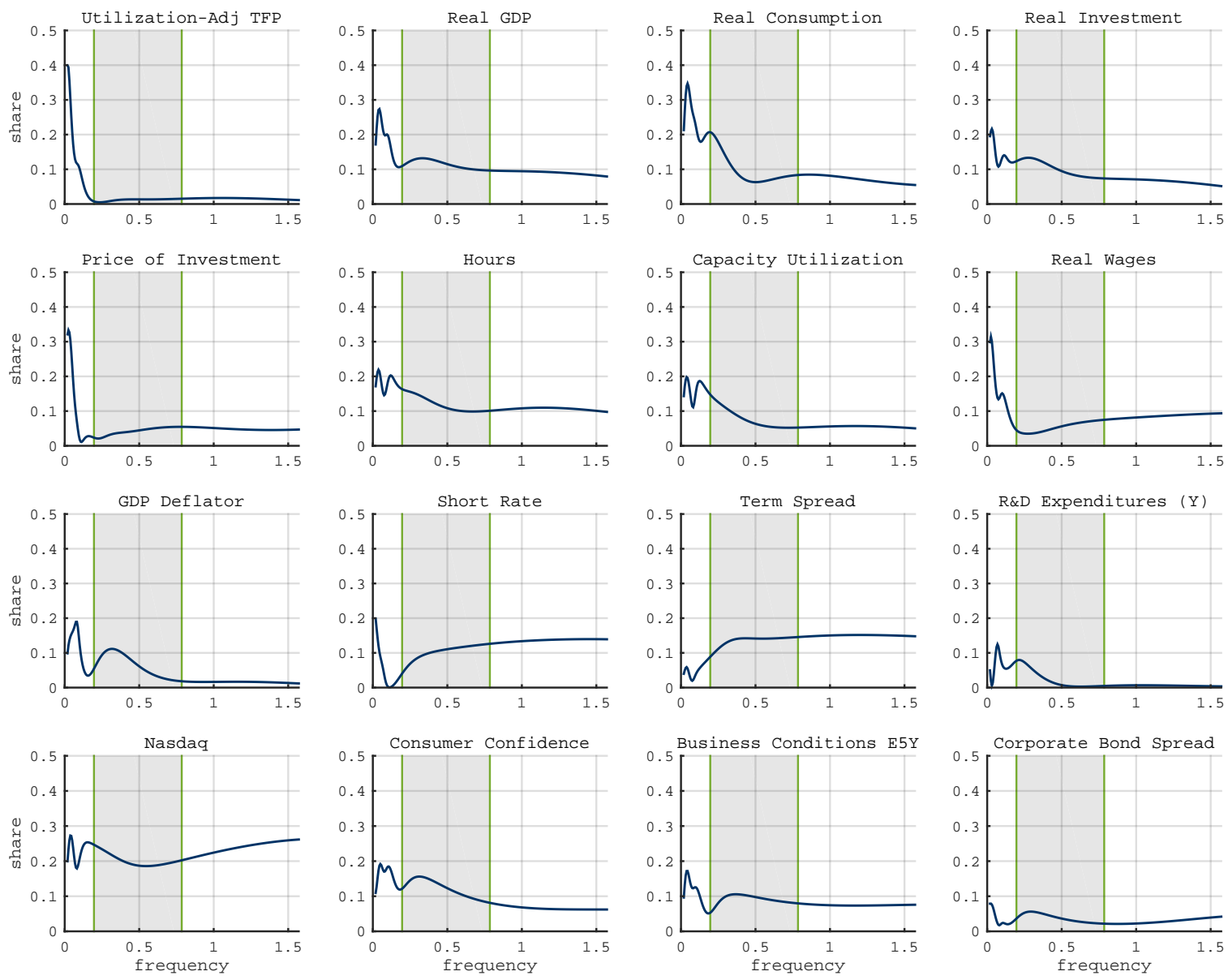

Note: Share of error variance accounted for by technology news shock identified with patents-based external instrument. VAR(4) with standard macroeconomic priors. Estimation sample 1971-I : 2016-IV; Identification sample 1982-I : 2006-IV. Shaded areas delimits business cycle frequencies (between 8 and 32 quarters). 


\title{
C Additional Details on the Patent Data
}

\author{
Figure C.I: Allowance Rates
}

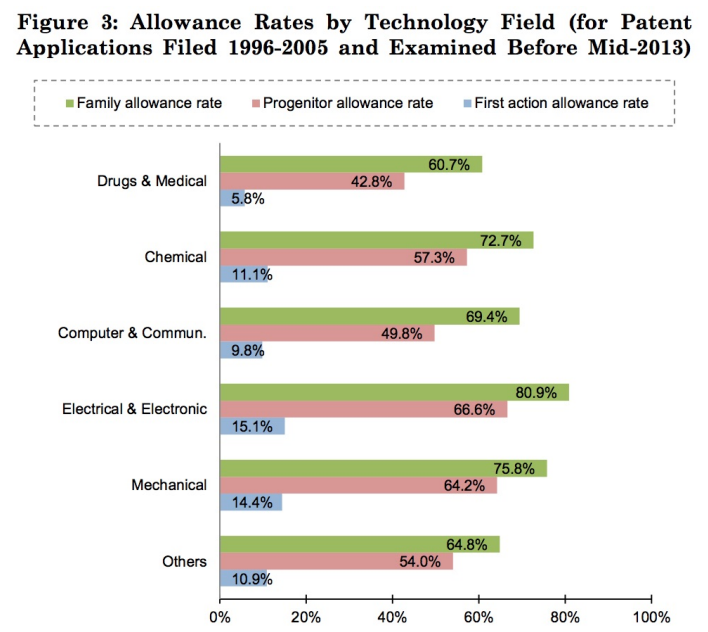

\section{Figure A1: Trends in Allowance Rates with Adjustments for} Censoring, for Applications Filed Between 1991-2010

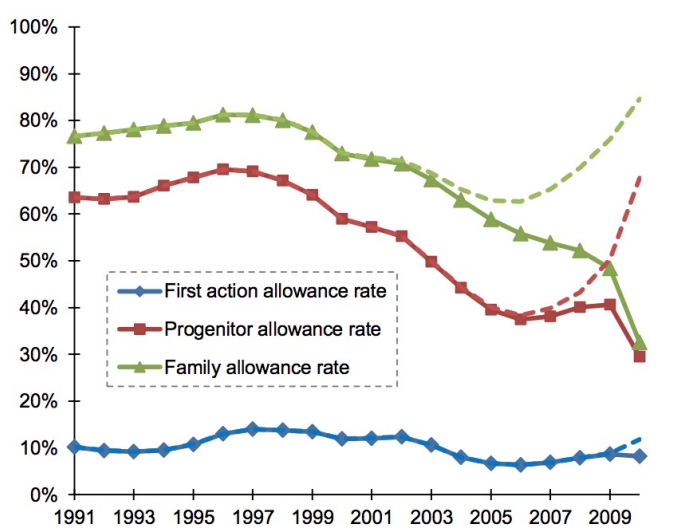

Note: [LEFT]: Allowance rates across the six NBER patent-technology fields for applications filed at the USPTO for the first time between 1996 and 2005 and examined before mid2013. (i) first-action allowance rate: proportion of progenitor applications allowed without further examination; (ii) progenitor allowance rate (or simply, allowance rate): proportion of progenitor applications allowed without any continuation procedure, and (iii) family allowance rate: proportion of progenitor applications that produce at least one patent, including the outcomes of continuation applications that emerge from progenitor applications. [RIGHT]: Trends in allowance rates from 1991 to 2010, all categories. Source: Carley et al. (2015).

Table C.I: Lagged Information in Patents Applications

\begin{tabular}{lccccccc}
\hline & $F_{1}$ & $F_{2}$ & $F_{3}$ & $F_{4}$ & $F_{5}$ & $F_{6}$ & $F_{7}$ \\
\cline { 2 - 8 } Wald Test & $9.215^{* * *}$ & 1.252 & 1.835 & 0.642 & 1.437 & 0.256 & 0.209 \\
p-value & 0.000 & 0.293 & 0.126 & 0.634 & 0.226 & 0.905 & 0.933 \\
\cline { 2 - 8 } Adj R & 0.790 & 0.732 & 0.738 & 0.732 & 0.736 & 0.727 & 0.726 \\
$\mathrm{~N}$ & 131 & 131 & 131 & 131 & 131 & 131 & 131 \\
\hline
\end{tabular}

Notes: Numbers reported are Wald test statistics for joint significance of the first 4 lags of each factor $F_{t}$. The factors are extracted from the quarterly dataset of McCracken and $\mathrm{Ng}$ (2015). The dependent variable is the quarterly growth rate of utility patents applications: $p a_{t}=100\left(\ln P A_{t}-\ln P A_{t-1}\right)$. All the regressions include own 4 lags, regulation dummy and constant. The regulation dummy captures the legal changes in the patents application process implemented in September 1982, June 1995, and March 2013. $*, * *, * * *$ denote statistical significance at 10,5 , and $1 \%$ respectively. 


\section{Figure C.II: Cumulative disposal proportion By NBER CATEgory}

Figure 13: Cumulative disposal proportion by NBER category, January 2002 cohort.
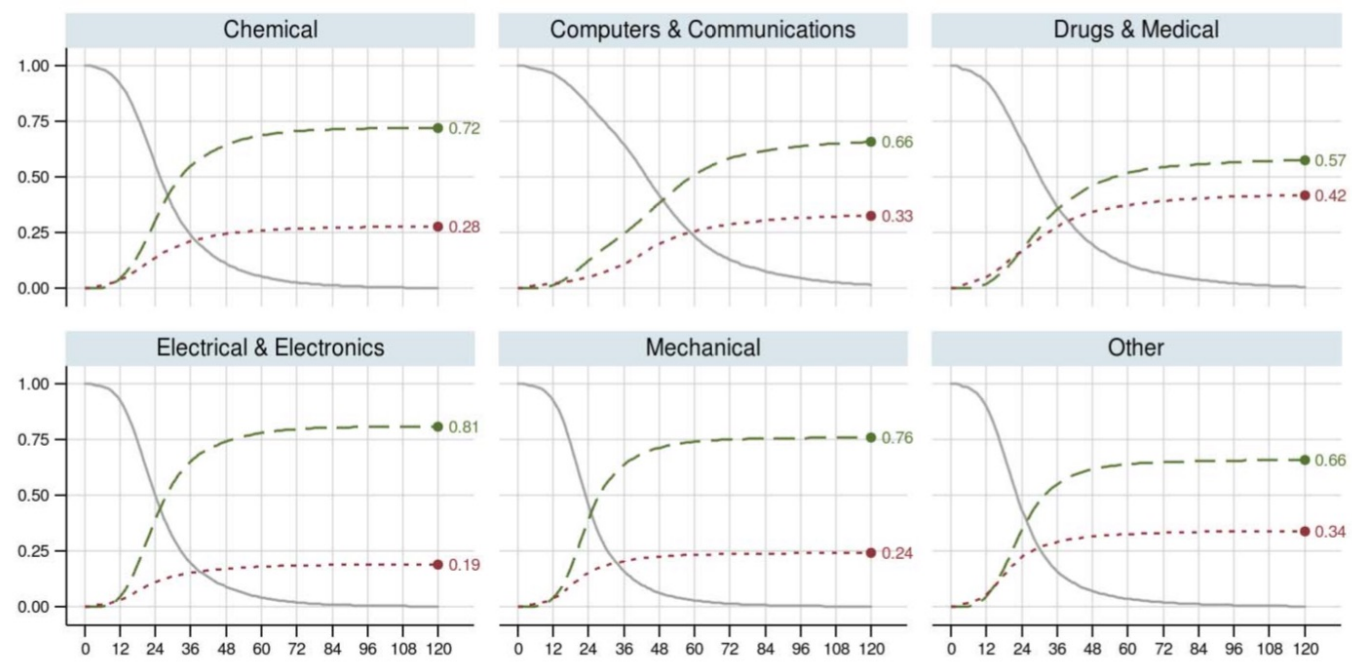

Months since filing

Pending $\quad-----$ Issued

Abandoned

Source: Marco et al. (2015).

Figure C.III: Patent Applications, Abandonments and Issuance

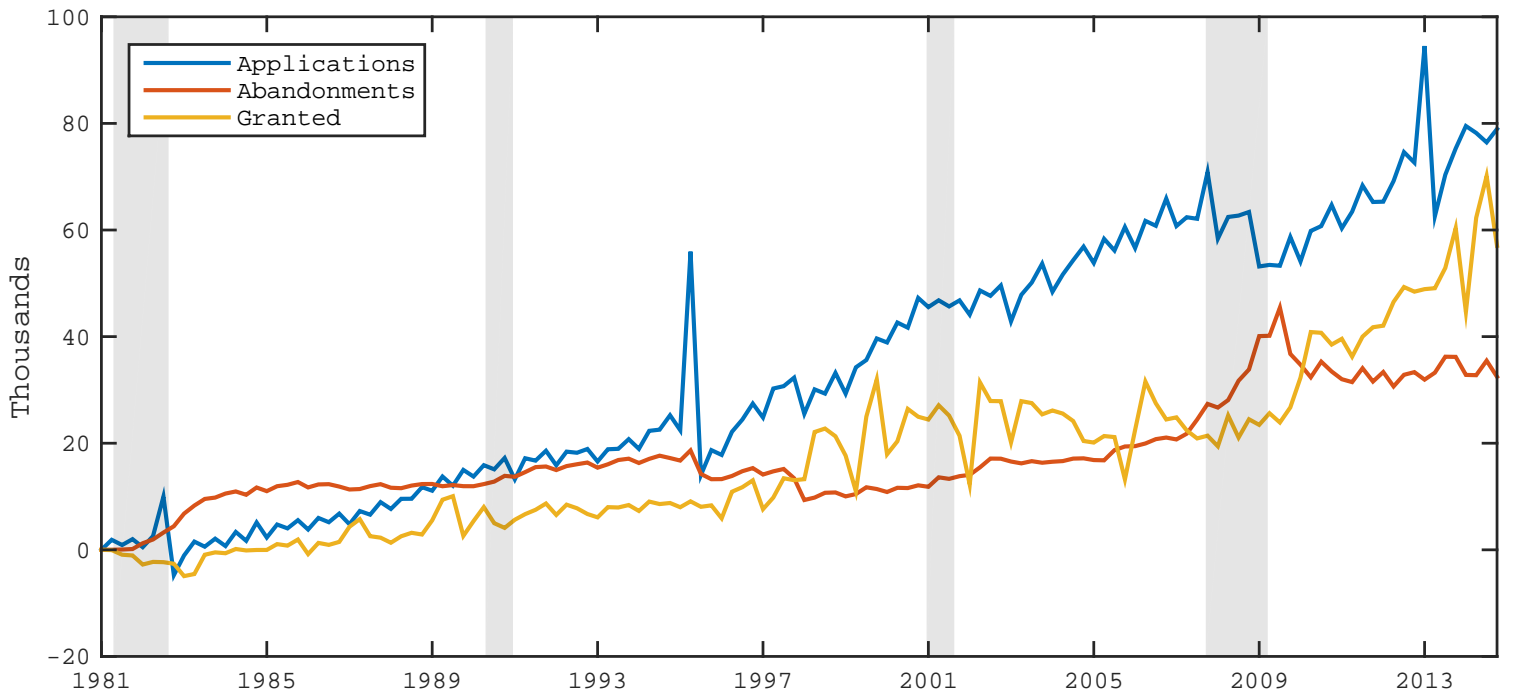

Note: Total number of applications (teal), abandonments (orange) and granted patents (yellow) across all NBER categories. Quarterly figures obtained as sum of monthly readings, 1981-Q1=0. Shaded areas denote NBER recession episodes. 


\section{Table C.II: NBER Patents Classification}

\begin{tabular}{|c|c|c|c|}
\hline Category & Category Name & Sub-category & Sub-category name \\
\hline 1 & Chemical & $\begin{array}{l}11 \\
12 \\
13 \\
14 \\
15 \\
19\end{array}$ & $\begin{array}{l}\text { Agriculture, food, textiles } \\
\text { Coating } \\
\text { Gas } \\
\text { Organic compounds } \\
\text { Resins } \\
\text { Misc. (chem) }\end{array}$ \\
\hline 2 & Computers and Communications & $\begin{array}{l}21 \\
22 \\
23 \\
24 \\
25\end{array}$ & $\begin{array}{l}\text { Communications } \\
\text { Computer hardware and software } \\
\text { Computer peripherals } \\
\text { Information storage } \\
\text { Electronic business methods and software }\end{array}$ \\
\hline 3 & Drugs and Medical & $\begin{array}{l}31 \\
32 \\
33 \\
39\end{array}$ & $\begin{array}{l}\text { Drugs } \\
\text { Surgery, medical instruments } \\
\text { Biotechnology } \\
\text { Misc. (drugs and medical) }\end{array}$ \\
\hline 4 & Electrical and Electronics & $\begin{array}{l}41 \\
42 \\
43 \\
44 \\
45 \\
46 \\
49\end{array}$ & $\begin{array}{l}\text { Electrical devices } \\
\text { Electrical lighting } \\
\text { Measuring, testing } \\
\text { Nuclear, X-rays } \\
\text { Power systems } \\
\text { Semiconductor devices } \\
\text { Misc. (elec) }\end{array}$ \\
\hline 5 & Mechanical & $\begin{array}{l}51 \\
52 \\
53 \\
54 \\
55 \\
59\end{array}$ & $\begin{array}{l}\text { Materials processing and handling } \\
\text { Metal working } \\
\text { Motors, engines, parts } \\
\text { Optics } \\
\text { Transportation } \\
\text { Misc. (tech) }\end{array}$ \\
\hline 6 & Others & $\begin{array}{l}61 \\
62 \\
63 \\
64 \\
65 \\
66 \\
67 \\
68 \\
69\end{array}$ & $\begin{array}{l}\text { Agriculture, husbandry, food } \\
\text { Amusement devices } \\
\text { Aparel and textile } \\
\text { Earth working and wells } \\
\text { Furniture, house fixtures } \\
\text { Heating } \\
\text { Pipes and joints } \\
\text { Receptacles } \\
\text { Misc. (others) }\end{array}$ \\
\hline 7 & Not Classified & 70 & Not classified \\
\hline 8 & Missing & 80 & Missing \\
\hline
\end{tabular}

Notes: NBER classifications of patents and the sub-categories as in Marco et al. (2015). The classification used by USPTO, US Patent Classification (USPC), involves many classes. To address the issues complications of USPC, Hall et al. (2001) developed a hierarchical classification. Their proposal was to aggregate USPC classes into 37 (two-digit) sub-categories, which are further aggregated into six main categories. They applied their classification strategy to the National Bureau of Economic Research (NBER) Patent Citations Data File. However, the use of this data set has been limited due to its coverage of only the patents granted. Marco et al. (2015) build upon Hall et al. (2001) and merge NBER Patent Citations Data File with PTO data resources to classify NBER sub-categories beyond only granted applications. We aggregate the utility patent counts for all sub-categories except non-classified and missing patent counts. 


\section{Additional Material}

The impulse response functions reported in this Appendix are all scaled such that the peak response of utilization adjusted TFP equals to $1 \%$.

\section{Figure D.I: IRFs Full vs Pre-Crisis SAmple}
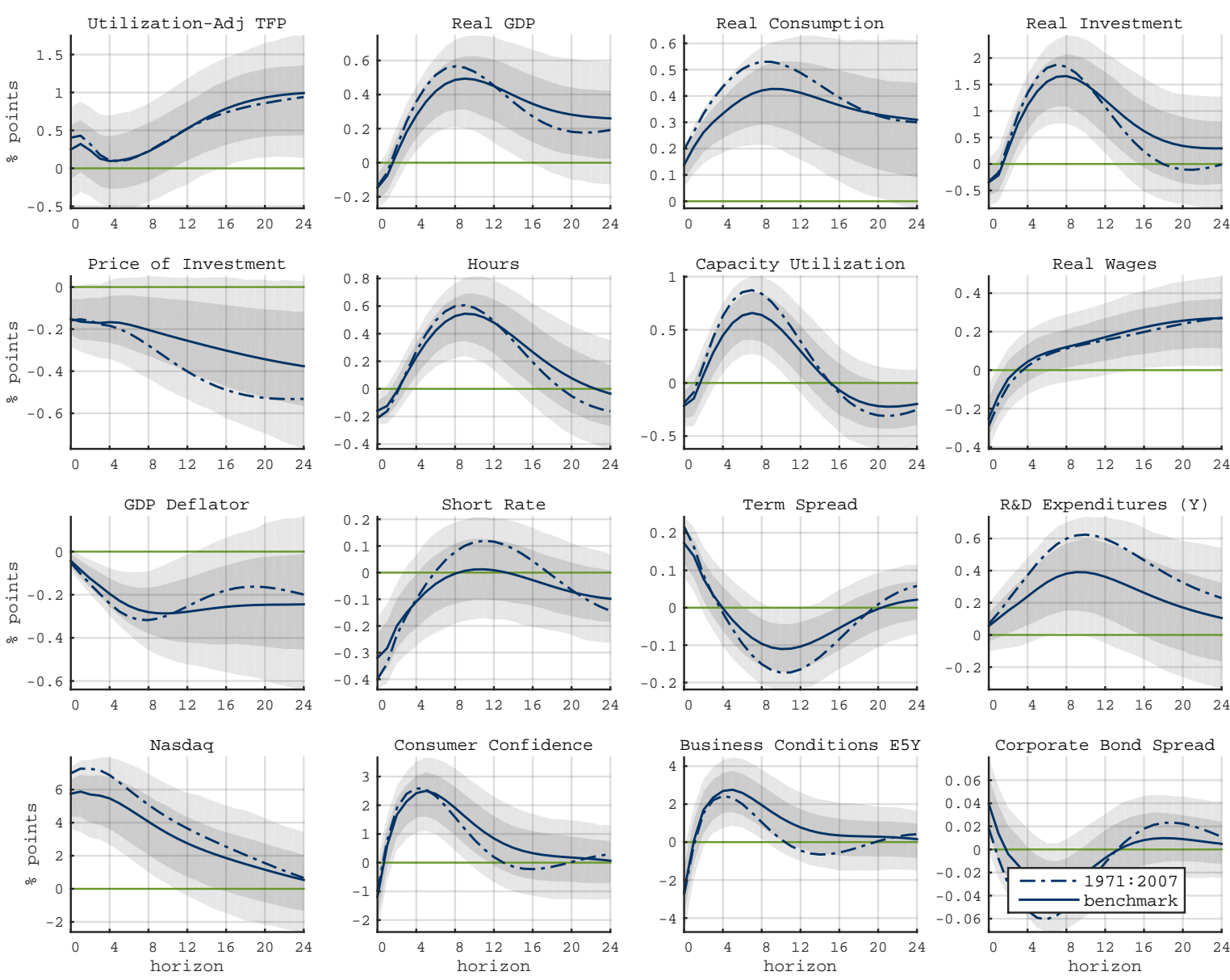

Note: Response of all variables to a technology news shock identified with patents-based external instrument. VAR(4) with standard macroeconomic priors. Estimation sample 1971-I : 2007-IV; Identification sample 1982-I : 2006-IV. Solid Lines: Instrument also controls for contemporaneous policy changes, benchmark. Dash-Dotted Lines: Instrument controls for SPF forecasts and lagged $p a_{t}$. Shaded areas denote $68 \%$ and $90 \%$ posterior coverage bands. 


\section{Figure D.II: IRFs Longer SAmple}
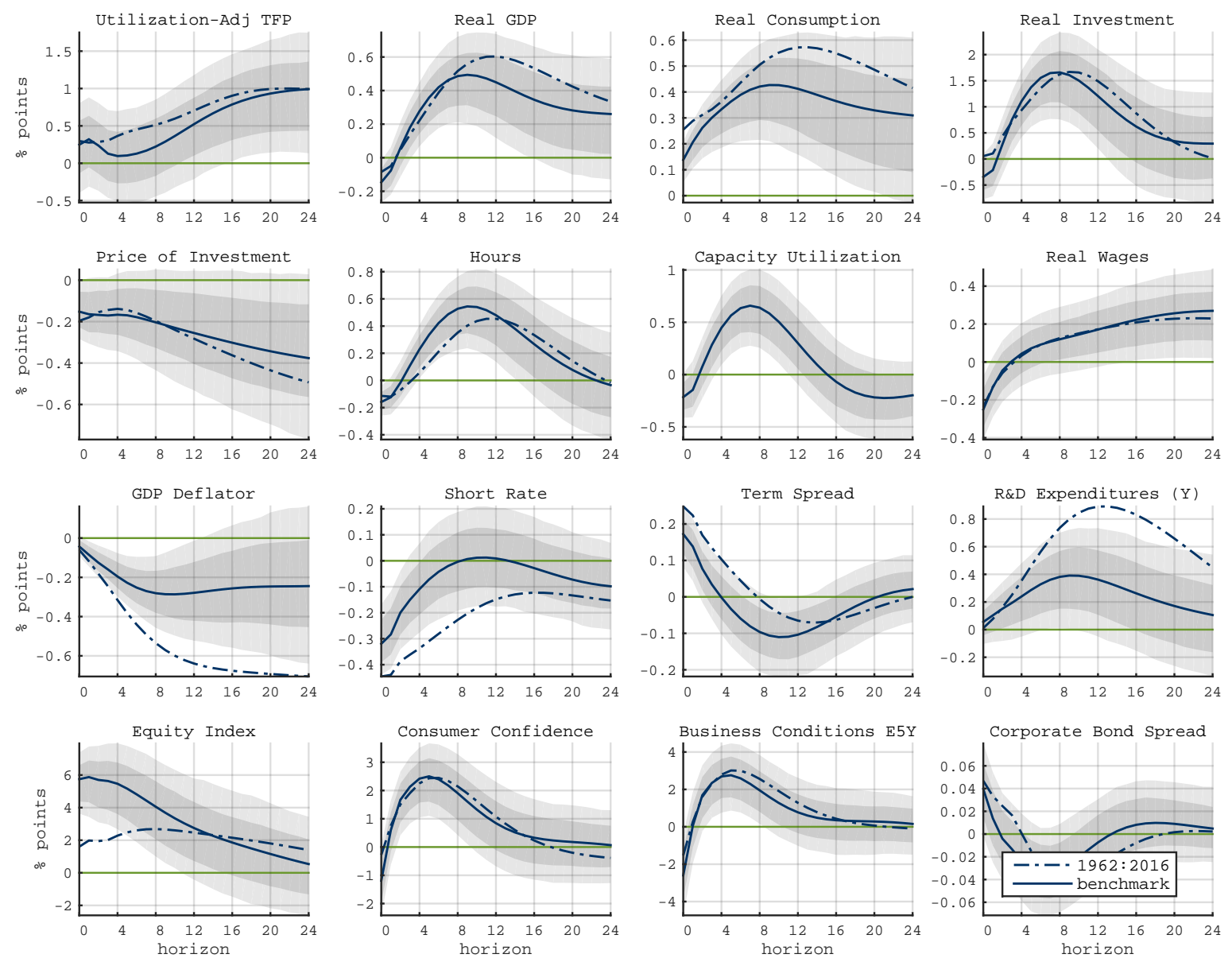

Note: Response of all variables to a technology news shock identified with patents-based external instrument. VAR(4) with standard macroeconomic priors. Solid Lines = Estimation sample 1971-I : 2016-IV; Identification sample 1982-I : 2006-IV. Dash-dotted Lines: Estimation sample 1962-I : 2016-IV; Identification sample 1982-I : 2006-IV. The equity index on the longer sample is the S\&P 500 shown in the Nasdaq subplot as a dashed-dotted line. Shaded areas denote $68 \%$ and $90 \%$ posterior coverage bands. 


\section{Figure D.III: IRFs with Unemployment Expectations}
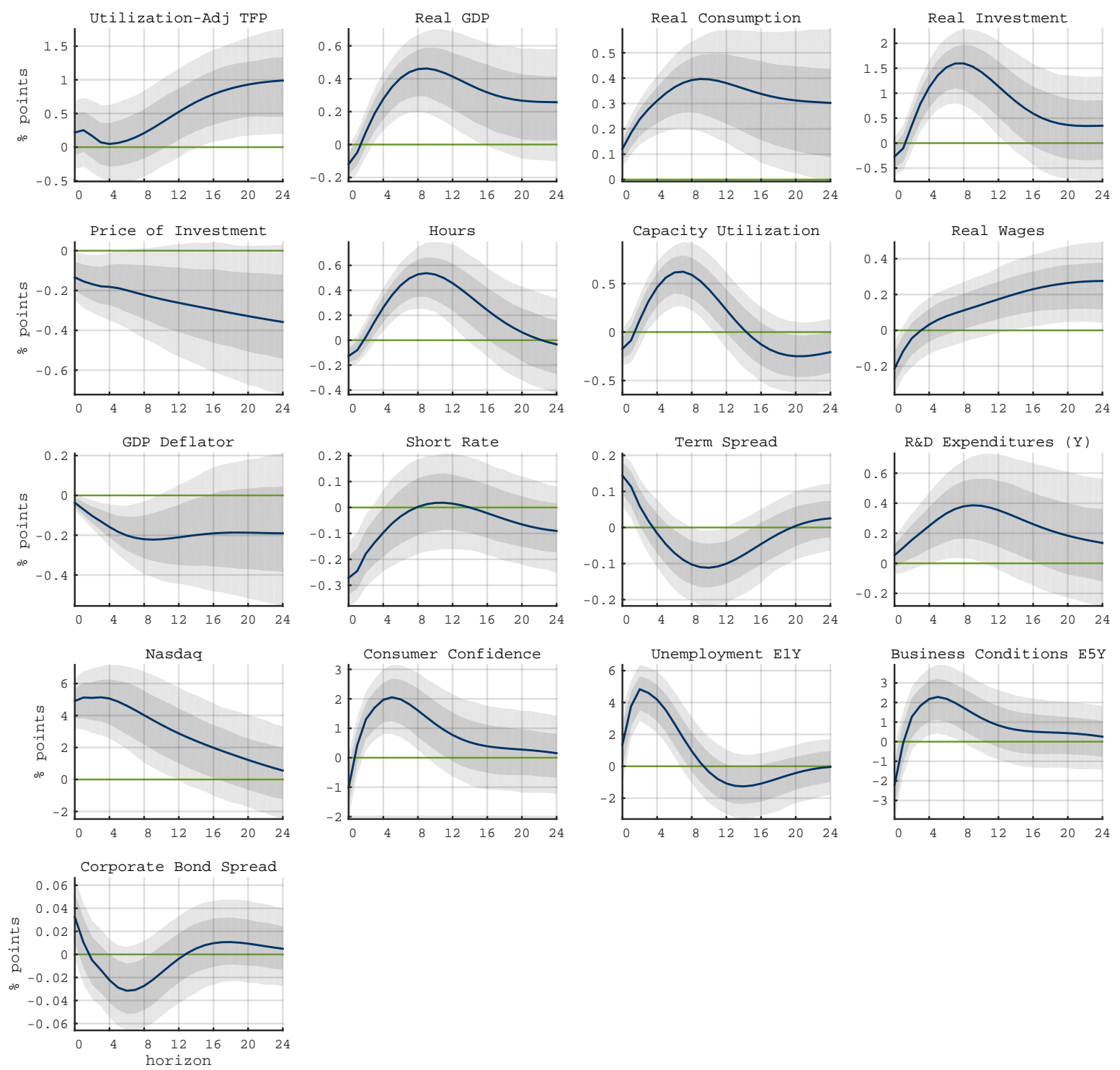

Note: Response of all variables to a technology news shock identified with patents-based external instrument. VAR(4) with standard macroeconomic priors. Instrument controls for contemporaneous policy changes. Estimation sample 1971-I : 2016-IV; Identification sample 1982-I : 2006-IV. Shaded areas denote $68 \%$ and $90 \%$ posterior coverage bands. 


\section{Figure D.IV: IRFs Pre-Crisis Sample: Instruments}
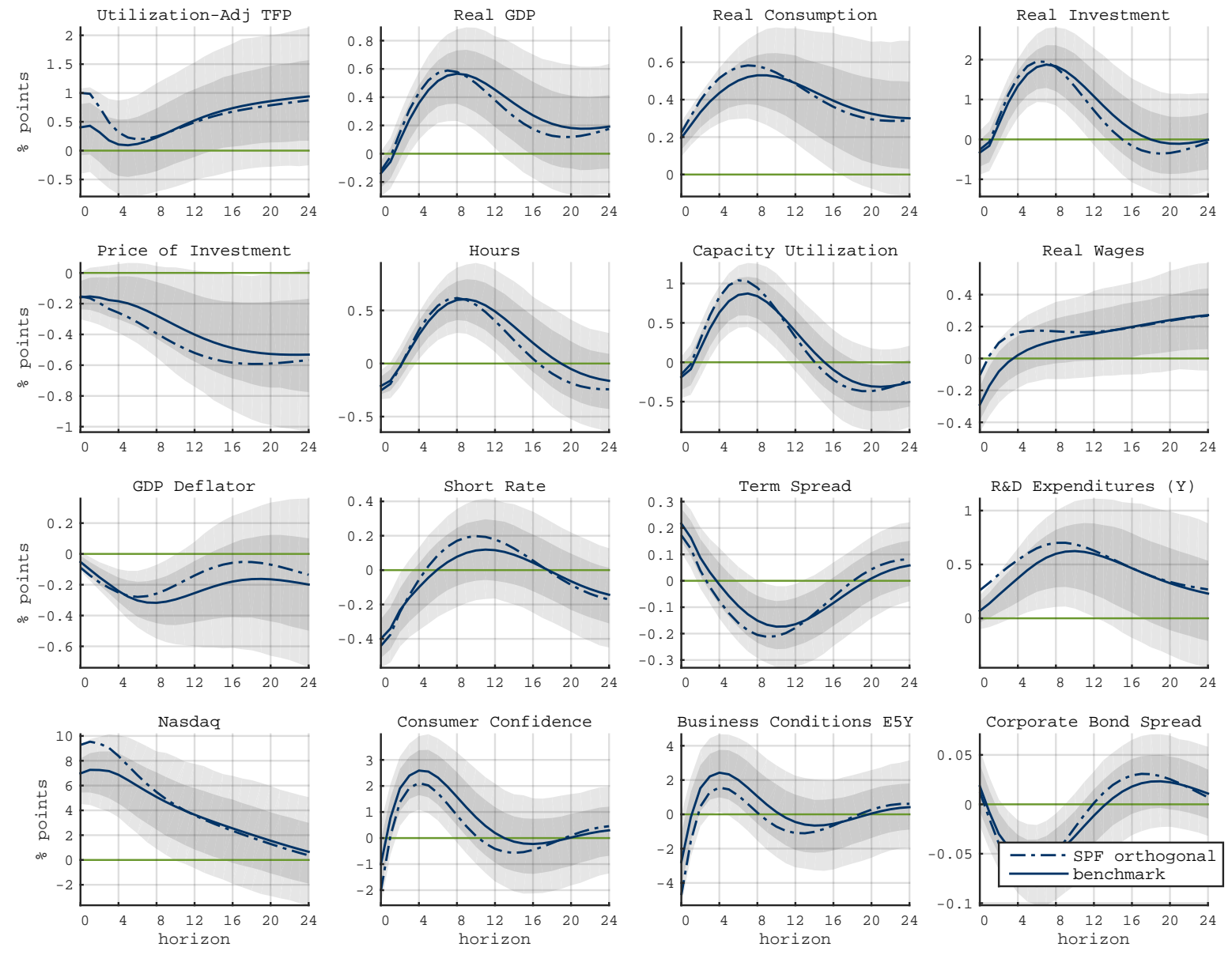

Note: Response of all variables to a technology news shock identified with patents-based external instrument. VAR(4) with standard macroeconomic priors. Solid Lines = Estimation sample 1971-I : 2007-IV; Identification sample 1982-I : 2006-IV. Dash-dotted Lines: Estimation sample 1971-I : 2007-IV; Identification sample 1982-I : 2007-IV. Shaded areas denote $68 \%$ and $90 \%$ posterior coverage bands. 